\title{
Assessment of the Efficacy of New Anti-Tuberculosis Drugs
}

\author{
Denis A. Mitchison ${ }^{*}, 1$ and Geraint R. Davies ${ }^{2}$
}

\author{
${ }^{I}$ Department of Cellular \& Molecular Medicine, St George's, University of London, Cranmer Terrace, London SW17 \\ ORE, UK \\ ${ }^{2}$ Wellcome Centre for Clinical Tropical Medicine/Department of Pharmacology, University of Liverpool, UK
}

\begin{abstract}
The pathology of tuberculosis in humans starts with an initial Ghon focus in the lungs followed by transmission of bacilli though the blood and lymph to other regions in the lungs and to other organs. While these bacilli usually lie latent without causing further disease, some $10 \%$ start foci of adult type disease usually starting in the sub-apical regions of the lungs. Bacilli multiply, killing tissue by caseation and then forming colonies within the caseum. Cavities form connecting to the air in whose walls vigorous bacillary multiplication occurs. The history of the development of anti-tuberculosis chemotherapy is described, starting with the use of multi-drug regimens to prevent the emergence of drug resistance and continuing with the shortening of the treatment period to 6 months by the incorporation in the regimens of rifampicin and pyrazinamide, which are the two drug responsible for bactericidal activity during treatment. Prospects for further shortening of treatment rest with the introduction of higher dosage with rifamycins and with new anti-tuberculosis drugs. These new drugs include the 8methoxyfluoroquinolones moxifloxacin and gatifloxacin which inhibit topoisomerases and protein formation, the diarylquinoline TM-207 which inhibits the mycobacterial ATP synthase and thus energy formation, the nitroimidazopyran PA-824 and the closely related OPC-676832 which are pro-drugs with uncertain modes of action and the pyrrole SQ-109, a cell wall inhibitor. Anti-tuberculosis drugs have widely variable pharmacokinetic characteristics but as they work efficiently together, it is unnecessary to match these when giving drug combinations. The effects of drug-drug interactions are usually small though the interactions with anti-retroviral drugs can pose problems. Dose sizes have usually been chosen to minimize side effects while retaining activity and thus tend to have low therapeutic margins, the exception being the margin of about 20 for isoniazid. The role of high plasma binding, important in limiting the efficacy of rifamycins, is uncertain for the newer drugs. Post antibiotic effects are vital to the prevention of drug resistance and need exploration for new drugs. The main aims of current drug development are (1) to shorten treatment, and (2) to make it more convenient, by for instance using widely intermittent regimens. The current techniques for measuring efficacy during drug development start with in vitro models, including the $\mathrm{Hu}$ /Coates models, which should contain bacterial populations resembling the bacterial persisters in lesions that are responsible for the long duration of treatment. The next stage is the mouse model of the chemotherapy of established tuberculosis, which has proved remarkably useful in assessing the value of the different drugs. The main problem in clinical assessment arises from the use of relapse after treatment as the main end-point, and the consequent need for very large numbers of patients required to provide measurable relapse rates in final phase III licensing studies. For this reason, surrogate studies are necessary in phase II which require much smaller numbers of patients. The first such investigations are phase IIA studies of early bactericidal activity which establish whether the drug given alone has bactericidal activity on cavitary bacilli and which can estimate the minimal effective dose of the drug, useful for decisions of dose size. The next step should be phase IIB studies which measure the rate of elimination of viable bacilli in sputum during the initial 8-weeks of treatment with various combinations of the new drug with established drugs. Measurement can be as (1) the proportion of patients with positive sputum at the end of the 8-weeks period, the easiest method but the least sensitive, or (2) as the speed with which sputum cultures become negative in a survival analysis, or (3) as the mean regression in modeling of serial sputum collections colony counts (SSCC). The relation between these surrogate estimates and the amoun of treatment shortening that can be obtained has still to be worked out.
\end{abstract}

Tuberculosis is amongst the most serious world-wide health threats. In 2005, there were 8.8 million new cases and 1.6 million deaths despite the availability of affordable and effective treatment [1]. The disease is most prevalent in tropical countries, particularly in sub-Saharan Africa. It has been increasing in prevalence in recent years mainly because of the spread of co-infection with HIV, though the incidence has probably peaked during the past 2-3 years [1].

*Address correspondence to this author at the Department of Cellular \& Molecular Medicine, St George's, University of London, Cranmer Terrace, London SW17 0RE, UK; Tel: +44 208725 5704; Fax: +44 208672 0234; E-mail:dmitchis@sgul.ac.uk
Fortunately, for the first time in thirty years, the antituberculosis drug development pipeline may be on the verge of delivering significant advances in therapy $[2,3]$. However, assessing the pharmacodynamics or efficacy of new agents at both the pre-clinical and clinical stages presents significant challenges and possible pitfalls. An understanding of the biological and clinical context of this effort is important in order to correctly identify and realize the potential of these new drugs. This review outlines principles derived from current understanding of the chemotherapy of tuberculosis and discusses their implications for assessment of efficacy at each stage of the development process. 


\section{PRINCIPLES}

\subsection{Pathology of Human Tuberculosis [4-10]}

Mycobacterium tuberculosis (MTB), transmitted by droplet nuclei containing as few as 2-3 organisms, establishes a characteristic "primary" infection (the Ghon focus) in the lungs of a naïve host. Invading MTB reside in the phagosomes of alveolar macrophages by actively preventing phagolysosomal fusion, and the outcome of infection in the "primary complex" is dependent on development of cellmediated immunity. In $90-95 \%$ of those infected, despite initial dissemination, multiplication is controlled by T-cell dependent activation of macrophages and successful granuloma formation. A state of "latent" infection occurs which does not always result in elimination of the infection since "adult type" disease develops in a further 5-10\% after a variable and often long period of latency. Infections with two or more strains seem to be fairly common indicating the inability of host immunity to prevent infection [11]. Adult disease starts in the sub-apical region of the lungs, where local $\mathrm{O}_{2}$ tension may be optimal, or sometimes in other organs, as a result of haematogenous dissemination from the primary complex or from direct implantation of a second infective dose of MTB. The granulomas may develop benignly, so that the MTB do not multiply or are killed. Alternatively, an ineffective immune response leads to bacillary multiplication, delayed hypersensitivity and death of all cell types in caseous necrosis of the granuloma. If this caseous material links to an open bronchus, an open cavity is formed in which immune control is ineffective. There is then very rapid extracellular multiplication, and small colonies of MTB are embedded in the cavity walls (Fig. 1). The high bacillary load in cavities allows the appearance of spontaneous drug resistant mutants typically present at a frequency of 1 in $10^{5}-10^{8}$ organisms. Such lesions, at low $\mathrm{pH}$, in varying stages of anaerobiosis and with bacillary nutrition switched to lipid utilisation [12], are the sites of the majority MTB population which chemotherapy must eliminate to prevent resistance emerging. This population may comprise a spectrum of subpopulations in growth phases, from exponential to stationary, and of varying age and nutritional requirement, determined by the complex microenvironment. There is also a minority population of intracellular bacilli, though its ability to survive between elimination in the benign granuloma and a shift to the extra-cellular environment at caseation is unknown. Drugs activities against each of these multiple bacillary subpopulations are very different $[4-7,9,10]$.

\subsection{Development of Chemotherapy}

The emergence of drug resistance was the main reason for the failure of streptomycin to provide a lasting cure for advanced tuberculosis $[13,14]$. Historically, this also proved to be true for every novel anti-tuberculosis drug introduced in monotherapy and the goal of research was the prevention of the emergence of resistance. Combination treatment with drugs that had different genomic targets afforded a solution to this problem. However, when any drug was given in combination with isoniazid, resistance still developed in some patients according to the ability of the drug to suppress bacterial multiplication and therefore growth of isoniazidresistant mutants (Table 1). Drugs could be graded in efficacy according to this ability. Complete inhibition of all bac- terial growth, and therefore an absence of failure during treatment, occurred when the efficacy of the drugs was improved and when combinations of 3 or 4 drugs were used [16-20]. Thus even potent new agents must form part of a combination regimen to prevent treatment failure and the emergence of resistance.
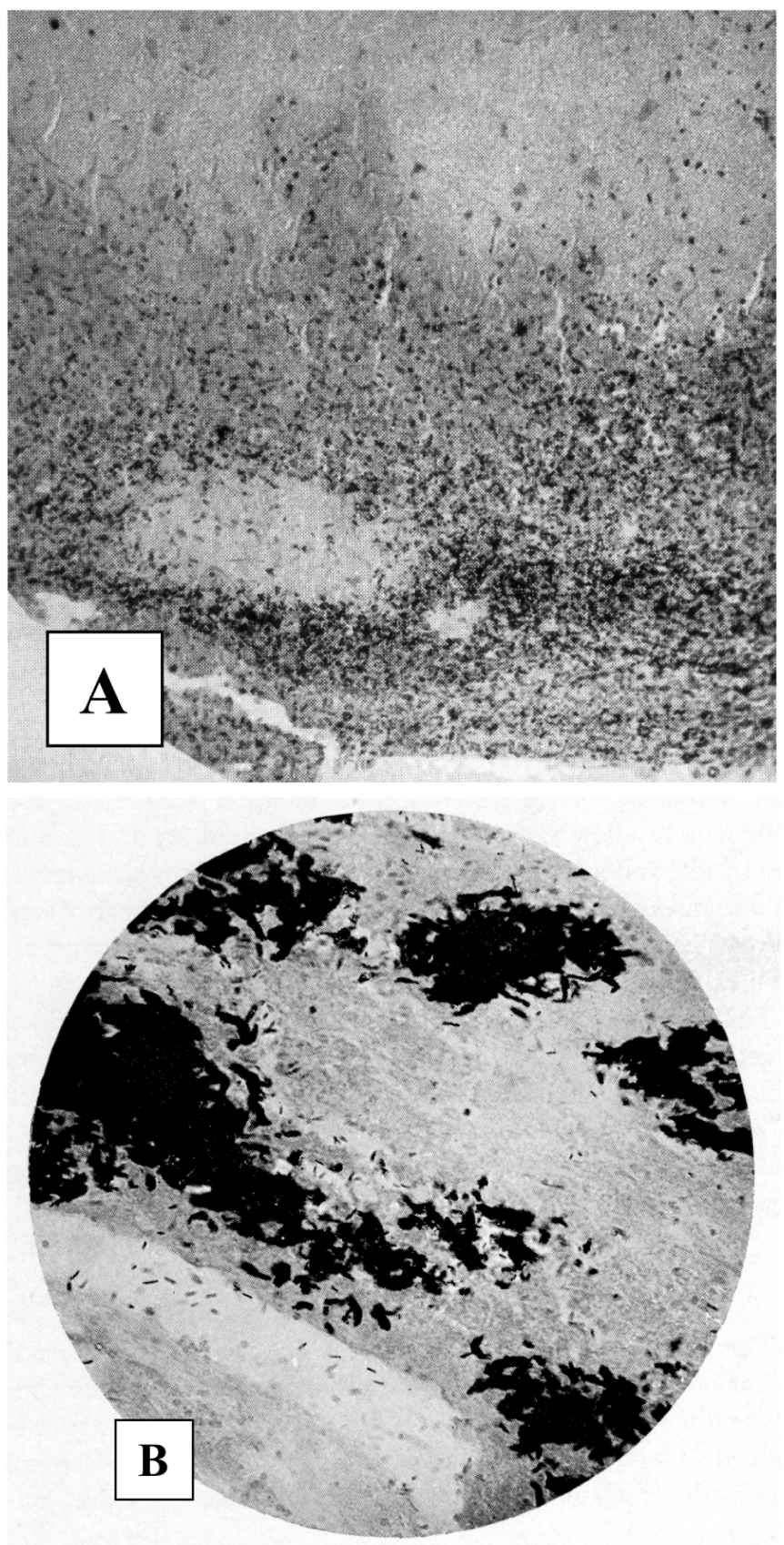

Fig. (1). Wall of a tuberculous cavity under low (A) and high magnification (B). Ziehl staining. Reproduced from Canetti [8]. (A) Low magnification $\times 140$. The lower part of the section is composed of softening casum, partly evacuated. The caseum is full of collies of bacilli. An area of collagenous tissue not yet caseated (lower left) is surrounded by the zone of necrosis; there is no growth of bacilli in the collagen. (B) High magnifaction x 660. Anrea under high magnifaction showing exuberant growth of bacilli.

From 1970 onwards, research began to focus on reducing the duration of therapy, at that time at least 12 months. A series of semi-factorial clinical trials introduced by the Brit- 
ish Medical Research Council evaluated "short-course" regimens, lasting 6-8 months $[19,20]$. The trial design used monthly sputum cultures to detect relapse, which subsequently became the primary end-point for assessing "sterilizing activity" and the ability of a drug to shorten treatment. A secondary surrogate end-point, the proportion of patients with negative sputum cultures for MTB at 2 months, was also introduced and found to correlate with relapse [21,22]. A statistical appraisal of 12 clinical trials found the 2-month end-point to have high specificity ( $82 \%)$ but rather low sensitivity (48\%) [23].

Table 1. The Occurrence of Failure with the Emergence of Drug Resistance During Therapy with Isoniazid and One other Drug [15]

\begin{tabular}{|c|c|c|}
\hline Isoniazid with & No. of Patients & Failure of Treatment (\%) \\
\hline \hline Rifampicin & 183 & 0.5 \\
\hline Streptomycin & 96 & 2 \\
\hline Ethambutol* & 105 & 4 \\
\hline PAS & 309 & 12 \\
\hline Thiacetazone & 423 & 16 \\
\hline
\end{tabular}

*The failure rate is slightly underestimated because streptomycin was also given for the initial 2 weeks.

The trials identified the strong sterilizing activity of rifampicin and pyrazinamide both independently and together (Table 2) and demonstrated that for pyrazinamide this activity was confined to the first two months [25-27]. These findings led to regimens comprising a 4-drug initial phase (HRZE standing for isoniazid, rifampicin, pyrazinamide and ethambutol) given for 1-2 months to eliminate the majority population and prevent resistance, followed by a 2-drug continuation phase of isoniazid with rifampicin or thiacetazone lasting 2-7 months to kill the residual population [20]. With the advent of the HIV epidemic, ethambutol replaced both streptomycin and thiacetazone resulting in the current standard 6-month regimen, abbreviated as 2HRZE/4HR. The 8month regimen of $2 \mathrm{HRZE} / 6 \mathrm{HE}$ was only recently evaluated in a controlled trial and was found much less effective [28]. No combination of current drugs at a duration of 4 months has proved capable of achieving relapse rates below the 5\% considered acceptable $[29,30]$ and the promise of "ultrashort course" chemotherapy has had to await the development of new drugs.

\subsection{Anti-Tuberculosis Drugs}

The discovery of current anti-tuberculosis drugs relied on serendipitous microbiological observations and selective screening of natural products from actinomycetes. However, a series of new drugs have recently entered clinical development [2]. The 8-methoxyquinolones, gatifloxacin and moxifloxacin are advancing into Phase III trials while a number of other agents have already reached Phase I/IIA including PA-824, OPC-67683, TMC-207 and SQ-109 (Fig. 2). With the exception of SQ-109, all of these drugs were found by empirical means, while the use of MTB genomic strategies for designing new drugs has so far met with difficulties.
Table 2. Clinical Trials Establishing the High Sterilizing Activity of Rifampicin and Pyrazinamide [19, 24]

\begin{tabular}{|c|c|c|c|}
\hline Regimen & $\begin{array}{c}\text { Total } \\
\text { Patients }\end{array}$ & $\begin{array}{l}\text { Relapse Rate } \\
\text { in 2-Year } \\
\text { Follow-up (\%) }\end{array}$ & $\begin{array}{c}\text { Proportions with } \\
\text { Negative Sputum } \\
\text { Cultures (\%) }\end{array}$ \\
\hline 6SHR & 152 & 3 & 69 \\
\hline $6 \mathrm{SHZ}$ & 153 & 8 & 66 \\
\hline 6SHT & 104 & 22 & 42 \\
\hline $6 \mathrm{SH}$ & 112 & 29 & 49 \\
\hline $2 \mathrm{STH} / 16 \mathrm{TH}$ & 133 & 3 & 56 \\
\hline 2SHRZ/4TH & 75 & 13 & \multirow{2}{*}{87} \\
\hline 2SHRZ/6TH & 81 & 0 & \\
\hline $2 \mathrm{SHR} / 4 \mathrm{TH}$ & 82 & 18 & \multirow{2}{*}{75} \\
\hline $2 \mathrm{SHR} / 6 \mathrm{TH}$ & 77 & 6 & \\
\hline
\end{tabular}

Initial number $=$ duration of treatment in months.

$\mathrm{S}=$ streptomycin, $\mathrm{H}=$ isoniazid, $\mathrm{R}=$ rifampicin, $\mathrm{Z}=$ pyrazinamide, $\mathrm{T}=$ thiacetazone. / indicates end of initial phase.

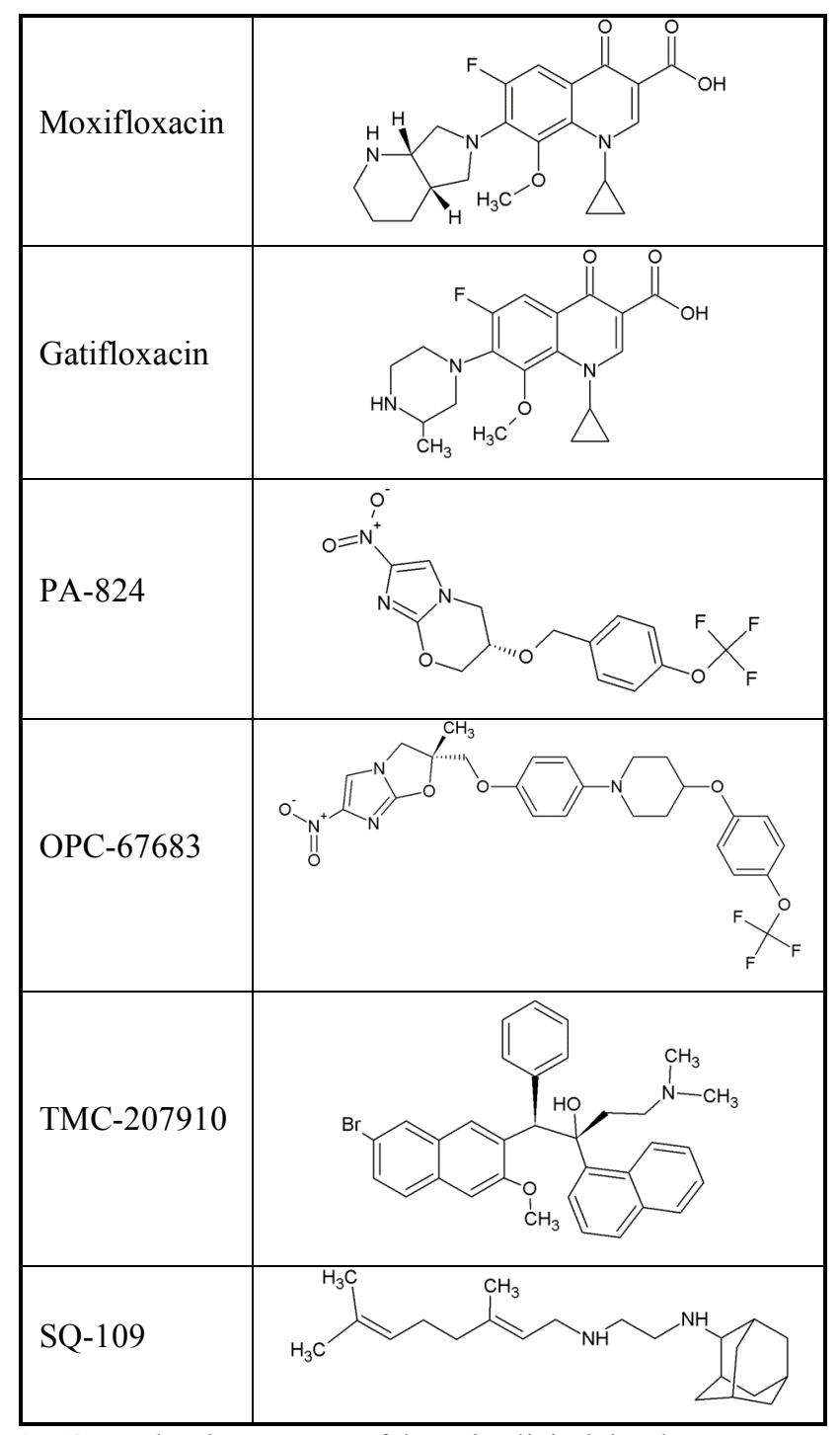

Fig. (2). Molecular structure of drugs in clinical development. 


\subsubsection{Mode of Action}

The mode of action of current drugs at the molecular level in MTB is known [31]. Formation of the bacterial cell wall is blocked by the pro-drug isoniazid [32], by ethambutol and by SQ-109. Transcription is blocked by rifampicin [33]. Streptomycin blocks protein formation at the ribosomal level. PA-824 and probably OPC-67683 are pro-drugs that eventually have an action on DNA resembling that of metronidazole [34]. TMC-207 blocks the mycobacterial ATP synthase and therefore respiration [35]. These drugs that are in current use act by antagonising bacterial enzymes and their activity reduces as bacterial multiplication and/or metabolism decreases. Pyrazinamide acts in an entirely different way $[36,37]$. It is a pro-drug converted to pyrazinoic acid. Pyrazinoic acid diffuses passively into the bacterial cell only in an acid environment, causing, acidification of the cell and membrane damage [37]. It is excreted by a membrane pump that requires energy, so that it's activity increases as bacterial metabolism decreases [37,38]. This feature makes it an ideal companion for any new drug that inhibits bacterial enzymes defined by the MTB genome. It probably does not act by inhibition of a specific enzyme (gene). In vivo, its activity may be targeted to inflammatory lesions at low $\mathrm{pH}$ and their resolution to a neutral $\mathrm{pH}$ may explain its lack of activity after two months [39]. This unusual pharmacodynamic action seems to be of critical importance in eliminating nonreplicating bacilli tolerant to the effect of other agents and shows that properties relevant to sterilizing activity could be overlooked by cell-free and target-based approaches to drug discovery. It also emphasizes the importance of incorporating a range of simple but relevant environmental factors, particularly a slightly acid $\mathrm{pH}$ and low $\mathrm{O}_{2}$ tension [40], into screening assays and pre-clinical development.

\subsubsection{Characteristics}

The physico-chemical and pharmacokinetic characteristics of anti-tuberculosis drugs are very diverse (Table $\mathbf{3}$ ), reflecting both their differing bacterial targets and probably the state and location of the bacterial subpopulation against which they are most active in vivo. Binding to plasma proteins is clearly an important factor in determining activity against extracellular bacilli within the rifampicin series, probably explaining the unexpectedly poor performance of rifapentine in clinical trials [43] (see section 1.5). The relevance of lipophilicity for sterilizing activity in vivo remains less clear.

\subsubsection{Dose Size}

Dose size has almost always been chosen empirically to keep toxicity low and is often only just sufficient to retain activity. The process usually takes years, as toxicity can only be established after testing large numbers of patients, as happened in the gradual reduction in the recommended dose size of ethambutol [44-46]. The therapeutic margin, namely the ratio between the usual dose size and the minimal effective dose, as determined in studies of early bactericidal activity (EBA), is therefore often quite low (ranging from 2 for streptomycin [47], 4 for rifampicin [48] to 20 for isoniazid [49]), in some cases simply reflecting a narrow window for toxicity but in others a lack of effective dose-ranging studies. For isoniazid, the current dose size of $300 \mathrm{mg}$ appears to achieve maximal effect $[49,50]$. For rifampicin, the low therapeutic margin in EBA studies, the rather low AUC/MIC ratio at current dose sizes [48] and the results of small clinical studies [51-53] suggest that there might be scope for increasing its dose size above the current $600 \mathrm{mg}$. Indeed, daily doses as high as $1800 \mathrm{mg}$ were initially used with acceptable toxicity $[54,55]$. The dosing interval for all these drugs has generally been fixed at 24 hours (or longer) since this has been shown both in animal experiments [56] and in clinical trials [57] to be as good as, or more effective than giving the dosage divided during the day.

\subsubsection{Interactions}

It is known that the pharmacokinetics of some first-line agents show substantial between-subject variability and that the elimination parameters of different drugs are not well matched. However, there is little justification for insisting on strict similarity of pharmacokinetic characteristics since the post-antibiotic effect greatly exceeds the dosing interval for most of the current first-line drugs (see section 1.5.1). An important theoretical condition for the avoidance of drugresistance in 2-drug therapy is that no bacterial growth occurs. The more effectively the first agent reduces the bacillary load and suppresses multiplication, the easier is the task for the second agent in controlling the emergence of resistance to the first agent. In conditions when the bacterial populations are small, so that no resistant mutants are present, 2-drug regimens or even monotherapy can be used without resistance emerging. Such regimens have been used in the treatment of bone and joint tuberculosis [58-60], in tuberculous meningitis [61] and in the continuation phase of treating pulmonary tuberculosis (in patients with initially sensitive bacteria) [62].

Table 3. Pharmacokinetic Properties of Anti-Tuberculosis Drugs $[41,42]$

\begin{tabular}{|c|c|c|c|c|c|}
\hline Drug & $\begin{array}{c}\text { Usual } \\
\text { Dose } \\
(\mathbf{m g})\end{array}$ & $\begin{array}{c}\text { Peak } \\
(\mathbf{m g} / \mathbf{L})\end{array}$ & $\begin{array}{c}\text { Half-Life } \\
\mathbf{( h )}\end{array}$ & $\begin{array}{c}\text { Protein } \\
\text { Binding } \\
\mathbf{( \% )}\end{array}$ & $\begin{array}{c}\text { MIC } \\
\text { M. tuberculosis } \\
\mathbf{( m g / L )}\end{array}$ \\
\hline \hline Isoniazid & 300 & $\begin{array}{c}5^{*} \\
4^{\dagger}\end{array}$ & $\begin{array}{c}1.3 \\
-\end{array}$ & 0.05 \\
\hline Rifampicin & 600 & 12 & 3 & 85 & 0.2 \\
\hline Rifapentine & 600 & 15 & 14 & 98 & 0.05 \\
\hline Rifabutin & 300 & & & & \\
\hline Streptomycin & 750 & 40 & 4 & 35 & 2 \\
\hline Pyrazinamide & 2000 & 40 & 8 & 0 & 20 \\
\hline Moxifloxacin & 400 & 4 & 12.5 & 40 & 0.5 \\
\hline Levofloxacin & 500 & 6 & 7.5 & 30 & 0.5 \\
\hline Ciprofloxacin & 500 & 2.4 & 4 & 35 & 1.0 \\
\hline Ethambutol & 1200 & 3 & 3 & 0 & 1.5 \\
\hline PAS (Na) & 12000 & 250 & 1 & - & 0.5 \\
\hline Thiacetazone & 150 & 2 & 12 & - & 0.4 \\
\hline Ethionamide & 500 & 3 & 2 & - & 0.6 \\
\hline
\end{tabular}

*Slow acetylator of isoniazid.

${ }^{\dagger}$ Rapid acetylator of isoniazid.

Thorough investigations in humans provide no evidence of pharmacokinetic interactions between isoniazid, rifam- 
picin, pyrazinamide and streptomycin [63], although such interactions have been observed in mouse models [64]. However, rifamycins are inducers of CYP3A4 making concomitant use of rifampicin with anti-retrovirals problematic.

\subsection{Plasma Binding}

The potential importance of plasma binding became evident in studies of early bactericidal activity (EBA) when penetration into cavities, as measured by the therapeutic margin (the ratio between usual dose size and dose at which EBA $=0$ ), was much smaller for rifampicin than for isoniazid despite similarities in their pharmacokinetics [43, 49]. This could be explained if only the unbound fraction of the dose, $15 \%$ for rifampicin and $100 \%$ for isoniazid penetrated into cavities. The concept also explained the unexpectedly poor results when rifapentine, with only $2 \%$ unbound, was given with isoniazid in the continuation phase of large clinical trials $[65,66]$. This phenomenon is of considerable current importance since several of the new drugs most advanced in development are highly or fairly highly plasma bound and might therefore be far less active than would seem likely simply from consideration of their MICs and plasma concentrations alone. It is important to realise that high plasma binding may not only associated with low activity but also with a long half-life, because binding slows renal excretion. The extent of binding can be manipulated by altering the drug molecule during its development and an interesting choice then becomes available. Increasing the proportion bound extends the half-life of the drug making it more suitable for intermittent administration (as for rifapentine). However, as binding increases, there is a parallel need to increase the dose size substantially and a drug that cannot be eliminated rapidly also poses a toxic risk

\subsection{Pharmacodynamic Responses}

\subsubsection{Post-Antibiotic Effects}

Since the ability of a drug regimen to maintain bacterial stasis throughout treatment is essential for preventing the emergence of drug resistance, the duration of a drug's antibacterial action must be established. When drug concentrations fall below the MIC in blood, and probably only a little later in lesions, further bacterial multiplication is prevented by the post-antibiotic effect (PAE) (Table 4), unless widely spaced (usually weekly) intermittent therapy is given. The effects of small doses of isoniazid are cumulative [69] and the PAE, preventing further multiplication, lasts for a maximum of about 6 days [67]. For rifampicin, the recovery from a dose is gradual and inhibition of growth lasts for 1-5 days, according to the size of the exposure to the drug [67]. Only when doses are spaced out as widely as every 7 days, does growth occur between doses $[44,70,71]$ Once this happens, therapy is less effective $[65,66,70,71]$ and drug resistance develops in a complex manner often with resistance to only one of the drugs or to each alone in separate sub-populations [70-72]. PAE is of great importance not only in the construction of intermittent regimens but also in preventing drug resistance arising from poor adherence to the regularity of drug taking [73]. PAE is the glue that makes the current standard regimen so resilient under widely different circumstances, but its importance is not widely appreciated.
Table 4. Post-Antibiotic Lag Periods After Pulsed Exposures to Antibacterial Drugs [67, 68]

\begin{tabular}{|c|c|c|c|}
\hline \multirow{2}{*}{ Drug } & \multirow{2}{*}{$\begin{array}{l}\text { Concentration of } \\
\text { Drug }(\mu \mathrm{g} / \mathrm{ml})\end{array}$} & \multicolumn{2}{|c|}{$\begin{array}{l}\text { Lag Period (Days) } \\
\text { After Exposure for: }\end{array}$} \\
\hline & & $6 \mathrm{hr}$ & $\begin{array}{l}24 \text { hr or More } \\
\text { (Maximal) }\end{array}$ \\
\hline Thiacetazone & 10 & 0 & 0 \\
\hline Thiocarlide & 10 & 0 & 0 \\
\hline Isoniazid & 1 & 0 & $6-9$ \\
\hline Ethionamide & 5 & 0 & 10 \\
\hline Cycloserine & 100 & 0 & $4-8$ \\
\hline Pyrazinamide & 50 & $5-9^{*}$ & \\
\hline Ethambutol & 10 & 0 & $4-5$ \\
\hline Streptomycin & 5 & $8-10$ & $8-10$ \\
\hline Rifampicin & $0-2$ & $2-3$ & $2-3$ \\
\hline Moxifloxacin & 100 & $6^{\dagger}$ & 15 \\
\hline
\end{tabular}

\subsubsection{Responses of Bacterial Populations}

Experimental and clinical trial data support the concept of at least two distinct pharmacodynamic responses during the treatment of human disease [74-76]. During standard therapy of new cases, the profile of sputum viable colony counts is biphasic with an early rapid kill, merging over the first 7 days into a later slower decline throughout the remainder of therapy (Fig. 3). Historically, these phases were referred to in clinical trials as "early bactericidal" and "sterilizing" activities. This phenomenon is likely to be due to heterogeneity of the bacillary population, with multiplying MTB being eliminated in the early phase and one or more poorly-replicating or static, antibiotic-tolerant "persister" subpopulations being eliminated in the late phase. Isoniazid is by far the most effective drug in the early phase [77] and is also slowly sterilizing when given alone in latent infection [78]. In current combination regimens, however, it has no apparent sterilizing action after the first few days [79] because elimination in the late-phase is strongly determined by the combination of rifampicin and pyrazinamide $[74,79,80]$ with the effect of pyrazinamide showing an apparent lag of a few days in starting $[39,74]$ and finishing by the end of two months [25-27]. Since rifampicin and pyrazinamide are responsible for the success of short-course chemotherapy, it is clearly the late phase, from 7 days onwards, that determines the length of therapy and on which attention must focus.

\subsubsection{Bacterial Environments}

Until quite recently, the relevant in vitro/in vivo pharmacodynamic characteristics of the current first-line agents were incompletely described and many in vitro studies did not take into account important factors such as environmental $\mathrm{pH}$ and $\mathrm{O}_{2}$ tension, growth phase of the organism and its intra- or extra-cellular location. For isoniazid, rifampicin and the fluoroquinolones, data obtained in vitro and in 
$\begin{array}{ll}\text { The Open Infectious Diseases Journal, 2008, Volume } 2 & \text { Mitchison and Davies }\end{array}$

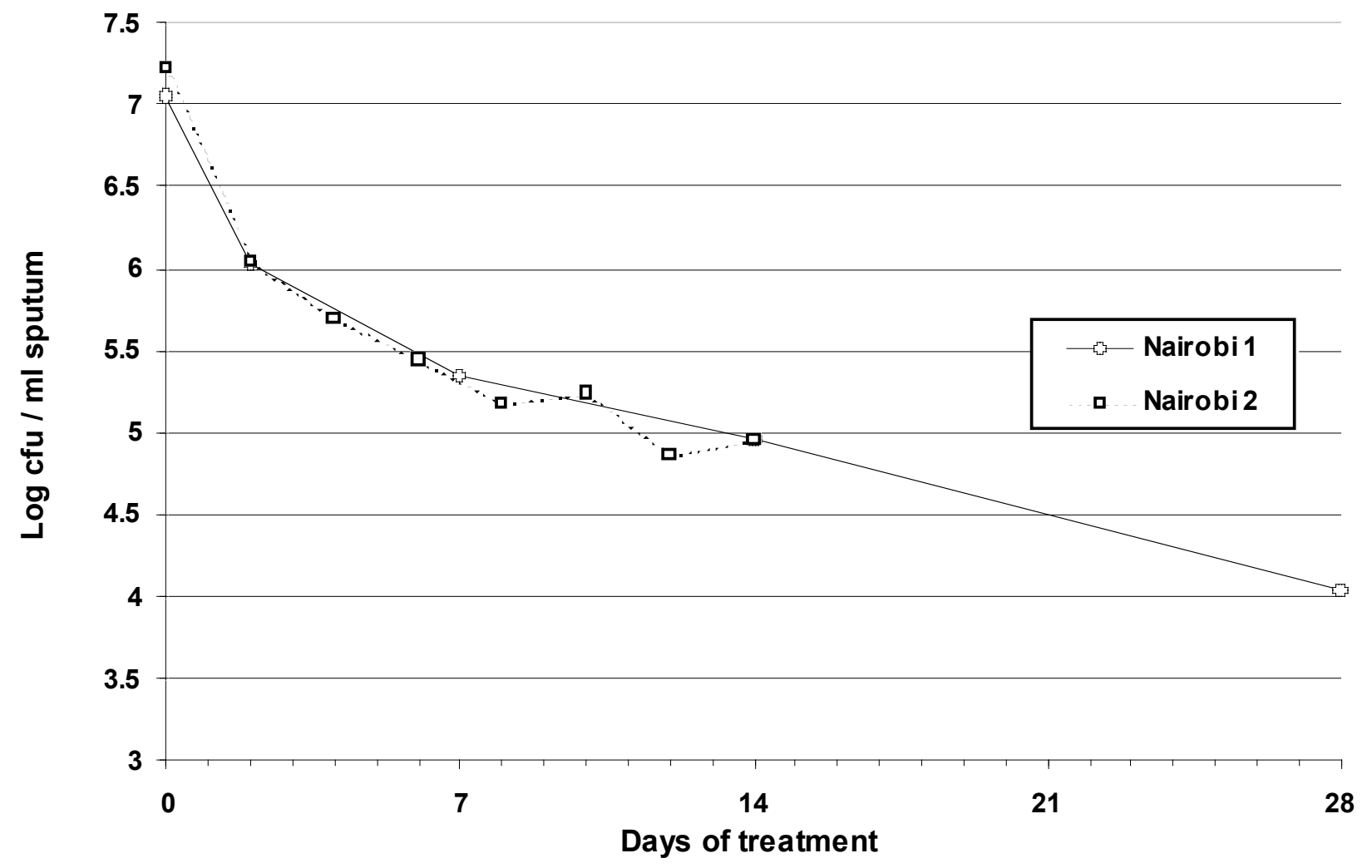

Fig. (3). Counts of viable MTB during therapy with regimens containing isoniazid. Data from [74, 75].

murine infections now support the AUC/MIC as the pharmacokinetic index best related to bactericidal activity [81-83]. However, in clinical studies, peak concentrations (Cmax) over MIC was found best related to the clinical response to monotherapy with isoniazid $[84,85]$. Critical information on this issue was obtained from dose fractionation studies in the mouse model which revealed time-dependent effects while the equivalent contrast between the responses of rapid and slow acetylators of isoniazid and between the responses in daily and intermittent clinical trials $[84,85]$ failed to show such an effect. While there is recent evidence indicating slightly better response in daily than in intermittent regimens $[28,86]$ the improvement is marginal. The reduction in efficacy with intermittent regimens seems unlikely to be equivalent to reducing the dose size to half or less. This might indicate that pharmacokinetic-pharmacodynamic (PKPD) relationships are different when the bacterial populations in murine infections are first exposed to the drugs, as in the mouse experiments, to those that exist after long continued exposure to the drugs in the persister populations of human lesions.

\subsubsection{Pharmacodynamic Models}

Simple in vitro pharmacodynamic models generally reflect conditions likely to be associated with early phase activity and can therefore represent the action of drugs such as isoniazid well. However, pyrazinamide, a remarkably potent sterilizing drug during its short period of activity in current regimens, is completely inactive in such simple models. A variety of more potentially relevant assays for sterilizing activity have been proposed. Microarray expression studies of the effect of hypoxia, NO exposure, nutrient limitation and phagocytosis [87] have defined a reasonably conserved core set of genes, the dosR regulon, controlling these related phenotypic responses induced in such models [88]. All of these factors may be of relevance in vivo and recent studies of bacilli excreted in sputum appear to confirm this [12]. It is clear however that the exact experimental conditions of such in vitro assays may greatly affect the growth phase and transcriptional activity of the test organisms.

\subsubsection{Synergism and Antagonism}

Information on pharmacodynamic synergism/antagonism has been studied in the human macrophage [89-91] and in both actively growing and non-multiplying in vitro systems [92-94] and in animal model $[64,95]$. Formal chequerboard studies and isobolograms have been reported only for logarithmic cultures [96].

The classical concept of a "bactericidal couple" with synergistic killing by two agents with well-matched plasma peaks does not seem relevant to tuberculosis therapy given the pharmacokinetic diversity noted above and the effect of PAE. Furthermore, the results with "split regimens", using alternating doses of rifampicin/ethambutol and isoniazid/pyrazinamide, did not differ from those obtained with conventional regimens in which the four drugs were given simultaneously either in murine [97] or in human studies [98].

\subsection{Surrogacy}

Throughout the development process, decisions should be made on the basis of endpoints chosen according to their biological plausibility, statistical properties, relevance to clinical outcomes and cost-effectiveness. As development proceeds, costs increase and the ability of the models and 
biomarkers used to predict accurately clinical activity increases in importance. In early clinical trials, this is referred to as "surrogacy": a biomarker for which adequate evaluation has been carried out may eventually be used as a "surrogate endpoint" to predict or even stand in for the definitive "clinical endpoint" of interest [99]. Though the demands may be less stringent, this concept is also of obvious relevance to pre-clinical testing. Two features of the current development effort in tuberculosis make these considerations important.

First, trialling an ineffective regimen in Phase III will be very costly. Such trials must be based on the relapse rate as an endpoint but the rate for the current comparator is $<5 \%$, requiring trials involving about 500 patients per arm for adequate power (Table 5). Secondly, selection of a small number of promising combination regimens from a reasonably large number of candidates will therefore be a necessity but it is unclear how and at what stage of development this is to be done.

Whether we are considering pre-clinical or early clinical data we need to be cautious since formal statistical evaluation for the vast majority of existing models or surrogate endpoints against relapse is currently inadequate. We need to recognize that even the best validated model systems, such as mouse studies and the proportion of patients with negative sputum culture at 2 months, are only validated to the extent of reproducing the performance of isoniazid, rifampicin and pyrazinamide in clinical trials $[21-23,100]$. This validation was only obtained after years of experience with these drugs and we have little assurance that the methods will be as successful with new drugs. This need not mean that we simply rule these data inadmissible since evaluation of surrogate endpoints is a process that is not just statistical and must begin somewhere [101]. We must however weigh the considerations referred to above, critically assess the data and arrange for ongoing evaluation to be built into our studies where that can be done.

Table 5. Numbers of Patients Required for Significant Differences $(p=0.05)$ in Relapse Rates in a 2-Arm Study with a Power of $95 \%$

\begin{tabular}{|c|c|c|c|c|c|}
\hline \multirow{2}{*}{ Relapse Rate in Treatment Arm } & \multicolumn{5}{|c|}{ Relapse Rate in Control Arm } \\
\cline { 2 - 6 } & $\mathbf{0}$ & $\mathbf{2}$ & $\mathbf{2 0}$ & $\mathbf{4 0}$ & $\mathbf{6 0}$ \\
\hline \hline 0 & - & 614 & 55 & 24 & 13 \\
\hline 5 & 241 & 852 & 113 & 33 & 16 \\
\hline 10 & 117 & 207 & 286 & 48 & 21 \\
\hline 15 & & & & 73 & 26 \\
\hline 20 & & & & 118 & 34 \\
\hline 25 & & & & & 46 \\
\hline 30 & & & & & 62 \\
\hline
\end{tabular}

\subsection{Power and Learning}

In addition to biological plausibility and existing degree of validation of our endpoints it is also important to consider their statistical form and power. It is useful to distinguish three different types of measure in common use in the therapy of tuberculosis: 1) proportions negative/positive at a particular time, usually 8 weeks, in clinical studies; 2) time to achieve negative cultures, and 3 ) rate of killing on a con-

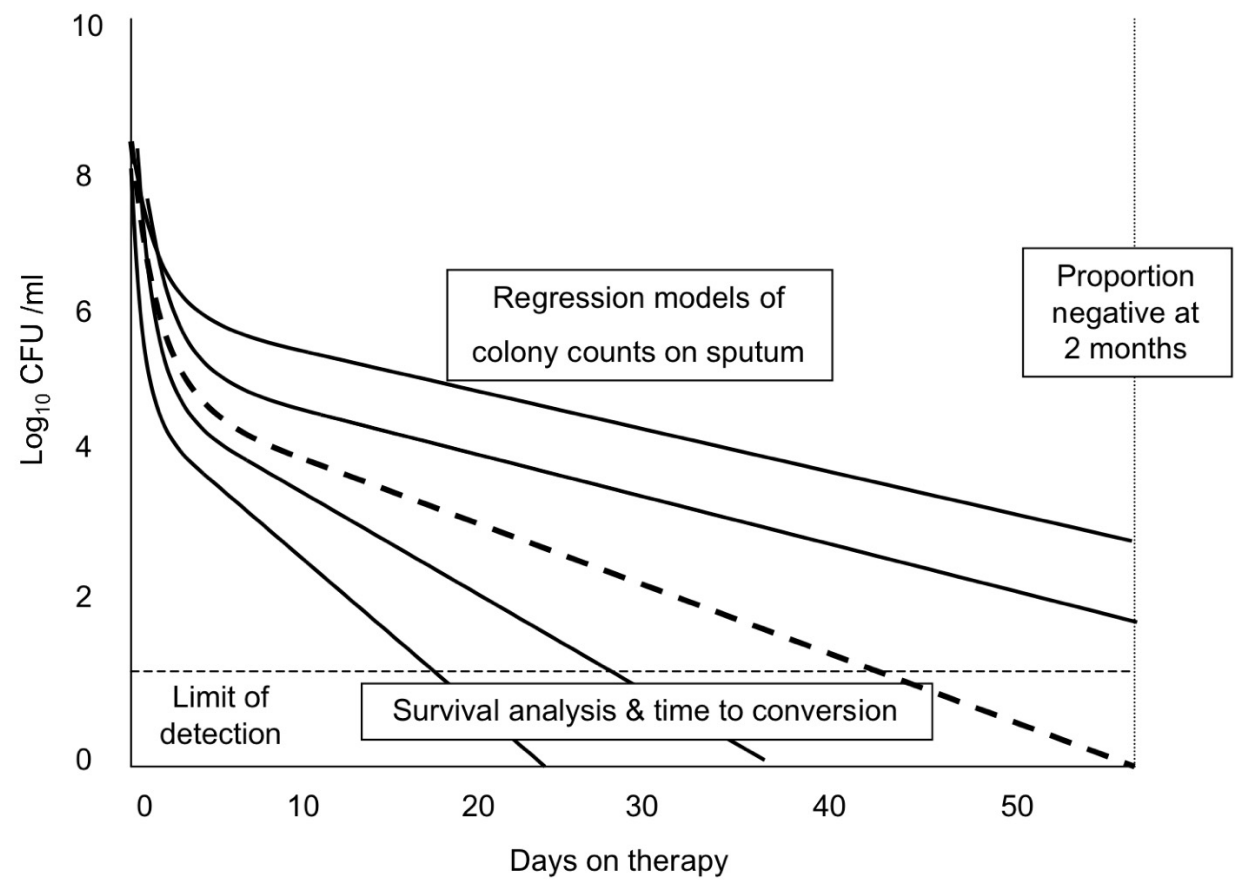

Fig. (4). Diagrammatic indication of how regression analyses of colony counts, speed of sputum conversion (by survival analysis) and proportion of patients negative at 8 weeks all measure the same rate of elimination of bacilli from sputum. Solid black lines represent the fall in bacterial content of sputum in individual patients. Dotted black line is the mean fall for the group. Proportion of patients negative at 8 weeks ( 2 of 4 ) is obtained from the result at 8 weeks. Speed of conversion is obtained from the treatment period until sputum conversion occurred. 
tinuous scale. The relationship between these measures is shown in Fig. (4).

If we accept that learning about the PKPD relationship should occur cumulatively throughout drug development $[102,103]$ then this will usually be most efficiently achieved using continuous measures. However in many areas (determination of the MBC in vitro, relapse rates in mouse studies and phase III clinical trials) proportions of bacterial, organ or sputum cultures negative at the end of a period of drug exposure are routine. Dividing results simply as positive or negative, whether as a result of technique or analysis can result in loss of information and statistical efficiency [104, 105]. It will also usually use a limited number of fixed time points giving a static, sometimes inflexible view of the data and requiring repeated piecemeal validation.

If more intensive longitudinal study designs are feasible but the endpoint is still binary then measures based on speed of attaining negative cultures can be used which will often prove to be superior [106-108]. Fully continuous measures such as the regression coefficient of viable bacterial count on time are likely to be the most powerful, but also the most logistically and analytically demanding [109]. From the point of view of evaluation it is worth pointing out that whichever type measure is chosen, each represents the underlying data-generating process more or less informatively and can in principle be expressed in terms of the others. Hence evaluation of one such endpoint will be relevant to the others.

Recommendations on duration of therapy have been based on relapse rates obtained in Phase III trials of regimens of varying length with the aim of obtaining rates $<5 \%$. Of particular interest are trials in which the same regimen was given for two different durations (Table 6) and a review of the results of trials of "ultra-short course" regimens suggests that six months may be conservative [110]. Clearly though it would be useful to have some indication of the likely length of a regimen from Phase II trials. Measures of the effect of time lend themselves more naturally to such forecasting, though this area remains to be developed.

\subsection{Aims in Drug Discovery}

The current top priority in tuberculosis drug development is to shorten the current duration of treatment to less than 6 months in order to reduce the burden of adherence on both patients and providers [2]. This goal must mean targeting "persisters" and therefore prioritizing the identification and enhancement of late-phase activity. PZA may be the only current first-line drug that ultimately survives introduction of new sterilizing drugs because of its unique mechanism of action and compatibility with anti-retrovirals. In the short-

Table 6. Factorial Study Designs Allowing Estimation of the Optimal Duration of Regimens [20]

\begin{tabular}{|c|c|c|c|c|c|}
\hline Site & Study & Regimen & Duration (Months) & Negative Sputum Culture at $2 \mathrm{~m}$ (\%) & Relapse Rate After 2-yr Follow Up (\%) \\
\hline \multirow[t]{8}{*}{ E. Africa } & 3 & 2SHRZ/TH & 6 & 87 & 13 \\
\hline & & & 8 & & 0 \\
\hline & & 1SHRZ/TH & 6 & 67 & 18 \\
\hline & & & 8 & & 7 \\
\hline & & 1 SHRZ/ $/ \mathrm{S}_{2} \mathrm{H}_{2} \mathrm{Z}_{2}$ & 6 & 75 & 9 \\
\hline & & & 8 & & 2 \\
\hline & 5 & 2SHRZ/H & 6 & 84 & 10 \\
\hline & & & 8 & & 3 \\
\hline \multirow[t]{12}{*}{ Hong Kong } & 1 & SHZ & 6 & 77 & 18 \\
\hline & & & 9 & & 5 \\
\hline & & $\mathrm{S}_{2} \mathrm{H}_{2} \mathrm{Z}_{3}$ & 6 & 70 & 24 \\
\hline & & & 9 & & 6 \\
\hline & & $\mathrm{S}_{2} \mathrm{H}_{2} \mathrm{Z}_{2}$ & 6 & 72 & 21 \\
\hline & & & 9 & & 6 \\
\hline & 2 & $2 \mathrm{SHRZ} / \mathrm{S}_{2} \mathrm{H}_{2} \mathrm{Z}_{2}$ & 6 & 81 & 23 \\
\hline & & & 8 & & 10 \\
\hline & & $4 \mathrm{~S}_{3} \mathrm{H}_{3} \mathrm{R}_{3} \mathrm{Z}_{3} / \mathrm{S}_{2} \mathrm{H}_{2} \mathrm{Z}_{2}$ & 6 & 94 & 6 \\
\hline & & & 8 & & 1 \\
\hline & 5 & $\mathrm{~S}_{3} \mathrm{H}_{3} \mathrm{R}_{3} \mathrm{Z}_{3}$ & 6 & 80 & 20 \\
\hline & & & 8 & & 3 \\
\hline \multirow{3}{*}{$\begin{array}{c}\text { Madras } \\
\text { India }\end{array}$} & 1 & $2 \mathrm{SHRZ} / \mathrm{S}_{3} \mathrm{H}_{3} \mathrm{Z}_{3}$ & 5 & 92 & 5 \\
\hline & & & 7 & & 0 \\
\hline & 2 & SHRZ & 3 & 91 & 20 \\
\hline
\end{tabular}


term there may still be a strong case for optimizing the dose size of rifampicin and further evaluation of rifapentine, rifabutin and perhaps 3-(4-cinnamyl piperazinyl imminomethyl) rifamycin SV (T9) [111-114] in terms of efficacy.

Achieving safe intermittent administration more suited to resource poor settings is now a secondary priority but still of importance. The use of the plasma binding characteristics of the long-acting rifamycins to optimise dose size and possible exploration of fluoroquinolones as companion drugs are currently under exploration. Furthermore, the high plasma binding of new drugs such as TM-207 and PA-824 make them eminently suitable for intermittent administration provided the toxicity of the high doses necessary can be avoided and the high doses of PA-824 are absorbed.

A third priority is the use of drugs with good sterilizing activity for chemoprophylaxis of disease in people who have been infected with MTB but remain healthy especially those who also have HIV infection. In recent years, rifamycins have been proposed in place of isoniazid but avoiding creation of wide-spread drug resistance to this key drug in treating active disease has meant that this approach has not been widely adopted. A CDC chemoprophylaxis study is in progress on the use of rifapentine, in a $900 \mathrm{mg}$ dose given once weekly so as to make supervision of drug taking easier. There is a possibility that more effective, safer sterilizing drugs could reduce the global burden of infection and disease, provided of course that people without disease would take them.

\section{METHODS}

\subsection{Drug Discovery and Screening}

New or improved anti-tuberculosis pharmacophores may be identified through various routes including (i) inhibition of growth or related physiological functions of MTB or closely related species in broth (ii) inhibition of growth or related physiological functions in cellular infection models (iii) sterilizing activity against non-replicating MTB in vitro (iv) identification of MTB genes required for growth or persistence (using allelic exchange [115], sequence-tagged transposon mutagenesis and TrasH $[116,117])$, elucidation of their functions and development of antagonists by high throughput screening. This is followed by optimization of binding or inhibition of previously characterised targets using combinatorial chemistry, molecular modelling and cellfree assays [118].

All of these methods have weaknesses and even at this stage, a clear definition of what counts as efficacy is important. Mechanism-based methods of identifying potential targets should generally focus on processes plausibly identified as relevant to persistence while ideally random screens would use assays which reproduce the conditions most closely associated with "sterilizing activity". In practice whether either of these conditions has been met may be uncertain. In the largest publicly-funded screening program (TAACF) [118], the primary in vitro screen (microplate alamar blue assay or MABA) simply demonstrates an arbitrarily "low" $\mathrm{MIC}_{90}(<6.25 \mu \mathrm{g} / \mathrm{ml})$ against H37Rv in broth and only compounds that pass this test generally progress to MICs against panels of resistant strains and determinations of $\mathrm{EC}_{90}$ in macrophage infection models. None of these tests reflects the effects of anaerobiosis, low $\mathrm{pH}$ or nutrient starvation. There are strong reasons for believing that MICs against actively growing MTB may differ widely from MICs against persistent or dormant MTB. Thus different analogs of PA824 have widely different ratios between these two types of MIC (personal communication, C Barry). The TAACF procedure defers "screening" of a relatively large number of compounds for sterilizing activity to later stages $(10 \%$ of about 80,000 submitted compounds "passed", only about $1000 \mathrm{had}$ an MIC $<1 \mu \mathrm{g} / \mathrm{ml}$ ) while it is quite likely that compounds with high sterilizing activity but low activity against actively growing MTB would not be identified.

\subsection{Pre-Clinical Development}

As far as efficacy is concerned, pre-clinical development aims to test the new molecule alone and in combination with other drugs in systems that more closely mimic sterilization in patients. These may be (1) in vitro models of drug action on bacilli resembling persisters (2) in vivo experimental therapy in the mouse model of chronic tuberculosis.

\subsubsection{In Vitro Models}

Simple in vitro assessments may include bactericidal action under conditions of reduced metabolic activity, such as suspension of MTB in non-nutrient buffer $[119,120]$ or at a variety of temperatures down to $21^{\circ} \mathrm{C}$ [80], where multiplication ceases. Another potentially important factor is the effect of $\mathrm{pH}$ over a range between 5.5 and 7.4 [121-123]. From the outset, it would also be helpful to have preliminary information about plasma-protein binding determined by for example equilibrium dialysis to ensure appropriateness of the drug concentrations selected for experiments.

Several in vitro experimental systems using nonreplicating cultures have been developed in an attempt to mimic the environmental and physiological conditions associated with persistence though they have generally received less attention in drug development than mouse models. Wayne developed sealed broth culture models in which bacilli gradually adapt to increasing anaerobiosis and enter two successive stages of "non-replicating persistence" with characteristics suggestive of bacilli recovered from chronic mouse models and human lesions [124, 125]. In particular, these bacilli demonstrate tolerance to drugs such as isoniazid and the fluoroquinolones but rifampicin retains activity. Metronidazole is also active in this system but this result has not been reproduced in mice [126], possibly because the redox potential of mouse lesions is not low enough to activate the drug [127]. Clinical trials of this agent are in progress but have not yet been completed. More recently, $\mathrm{Hu}$ et al. have carefully explored the heterogeneity of bacillary subpopulations present in stationary liquid cultures and developed a series of similar models of persistence incorporating explicit induction of drug tolerance using exposure to high concentrations of rifampicin [128]. Bacilli under these conditions are also impervious to the effect of isoniazid and tolerant to rifampicin, as expected. This approach reliably reproduces the sterilizing effect of pyrazinamide [38] and appears to have correctly ranked the activities of fluoroquinolones in Phase II studies [109, 129].

Studies of activity against bacilli residing in infected macrophages are commonly carried out but the conditions of 
these models vary considerably according to whether they use primary cells or well-characterised cell-lines, from which species these cells are derived, whether they are activated by cytokines and the multiplicity of infection used. Bacilli passaged through macrophages do show some similarities in microarray studies to those undergoing the environmental stresses used in the broth culture models and such models can account for cellular accumulation of drug. However, whether the persister population is predominantly intracellular remains controversial and predictions of such models have generally agreed less closely with those of clinical trials.

Another promising approach is that of in vitro PKPD modelling using hollow fibre systems which may be able to reproduce the conditions of the existing broth culture systems while simulating dynamic changes in drug concentrations more realistically, perhaps within monolayers of host cells [68].

Any proposed in vitro tests should contain controls that demonstrate that isoniazid, rifampicin and pyrazinamide have high, moderate and no activity against actively growing cultures, as in human therapy, while their relative activities would be low, high and high, respectively in the nonreplicating culture. In addition to testing individual drugs, at concentrations mid-way between MIC and peak concentrations, such models offer an economical way to test 2- and 3drug combinations and construct more extensive isobolograms/response surfaces then usually possible in mouse experiments from which promising combinations of drugs and trends in activity may be identified. They also offer a means of evaluating the joint PAE of agents in combination.

\subsubsection{Experimental Murine tuberculosis}

Mouse models have a longer history than in vitro models of sterilization but the experimental goals and conditions have varied substantially. For the purposes of experimental therapy of established disease, infection using a mousepassaged strain of MTB (usually H37Rv) may be introduced intravenously or by aerosol though the latter route is now preferred because of the ease with which large numbers of mice can be uniformly infected. Traditionally, protection studies for single agents in BCG vaccinated, outbred Swiss mice use a restricted intravenous or aerosol inoculum to prevent the bacillary population exceeding about $10^{5}$ and spontaneous resistance emerging during the study [130]. Treatment is begun after 24 hours and mortality after 28 days compared with controls. Recently a "rapid screening" model for single agents using aerosol infection with the virulent Erdman strain and GKO ( $\gamma$-interferon knock-out) mice has also been proposed for this purpose, but this method can be criticised for not studying a persistent MTB population [131].

For studies of combination therapy, inbred strains such as $\mathrm{Balb} / \mathrm{C}$ or $\mathrm{C} 57 \mathrm{BL} / 6$ are usually used to reduce inter-mouse variation in response and the inoculum is chosen so that after about 21 days the count in the organs approaches the lethal concentration of $10^{8} \mathrm{cfu} /$ organ before treatment is begun [64, 95]. This initial period allows the disease to become "established" and thus contain a proportion of persistent MTB. Regimens often lasting 6 months may be constructed resembling those used in patients by addition of the new drug to the standard combination of HRZ or its substitution in turn for each of the standard drugs with a $2 \mathrm{HRZ} / 4 \mathrm{HR}$ control, since ethambutol is not thought to contribute to bactericidal action. Samples of 6-10 mice are sacrificed at intervals from each arm, often monthly during treatment, and the spleens and lungs are homogenized and aliquots cultured in serial dilutions on plates, with and without drug, for incubation, colony counting and susceptibility testing. The results are evaluated by comparisons of the speed or rate of MTB killing due to the drug regimen, and also by proportions of mice that remain positive at certain time points, particularly at 2 months and later. Thus candidate combination regimens can be evaluated much more exhaustively than in human studies and the process of sterilization can in principle be monitored throughout treatment. This is currently impossible in clinical trials between the time that patients become sputum culture negative during the first few months until the point of relapse a year or more later.

Mouse models have been criticised on the grounds that they do not adequately reproduce some features of human disease. There have also been problems with inter-species scaling of the doses of agents, sometimes resulting in spurious findings, though equipotency is now usually assured by demonstrating similar AUC of drugs in both mice and humans [132]. More seriously, it is unclear exactly how the process of relapse in many mouse models relates to that seen in clinical trials. The classic system for studying relapse is the Cornell model in which mice are infected and left untreated for 3 weeks as in the established disease model [133]. They are then treated with isoniazid and high-dose pyrazinamide in the diet or drinking water for 12 weeks. Soon after the end of therapy, MTB cannot be found by any method in the organs during the "sterile phase", but if the mice are left untreated for several months relapses begin. Relapses are measured by culture of the organs, preferably in liquid medium, as either a positive or a negative culture result. Relapse can be accelerated by high dosage with corticosteroids. The aim in design is to achieve relapse rates in the order of $20-60 \%$ so as to achieve statistical efficiency with a reasonable number of mice. The system tends to be unstable, yielding either positive cultures during the sterile phase or too low a relapse rate for statistical efficiency [134]. Attempts have recently been made to attach assessments of relapse rates to the end of the established disease model by leaving mice untreated for 3 months after optimal periods of treatment and then culturing their organs for relapse [135]. This system tends to give a sharp end-point between a duration of treatment (perhaps for 2 months) followed by a high proportion of relapses and a slightly longer duration (perhaps for 3 months) that does not produce any relapses. Such a sharp end-point does not appear to occur in the treatment of human disease, making it difficult to translate the degree of shortening that might be obtained. Another problem in this design lies in the possibilities that the relapse rates may be low (0$5 \%$ ) when the number of mice required to establish differences becomes unrealistically large [136]. If they happen in the middle range $(20-60 \%)$, the numbers required are much smaller but the simulation of relapse rates in phase III clinical trials is less good. 


\subsection{Clinical Development}

\subsubsection{Phase I and II Studies}

Phase II studies proof of principle. It is the first time a drug is given to patients and often provides the first evidence of pharmacodynamic effect, usually on the basis of surrogate endpoints. This is difficult to do in Phase I development for tuberculosis for lack of a relevant pharmacodynamic response. The recently developed whole-blood bactericidal assay technique [137], an intracellular infection model incorporating the effects of protein binding and pharmacokinetics may offer a way of achieving this during Phase I/II studies and could be used to identify pharmacodynamic synergy during pharmacokinetic interaction studies in healthy volunteers. It can easily be adapted to the cross-over designs typically used unlike the measures available in patients which are irreversible once treatment has commenced. Currently, however, phase II studies are based on bacteriological assessments of viable $M$. tuberculosis in sputum since these are believed to be the most biologically relevant response and have been most extensively evaluated in clinical trials. Currently no other type of biomarker appears to offer any advantages and few have any support from evaluation studies.

Phase IIA studies of drugs given in monotherapy (termed "early bactericidal activity" or "EBA") aim to show that a drug has anti-tuberculosis activity at least in the early phase of treatment in humans and can also be used for preliminary dose selection by examining a range of dose sizes so as to estimate the minimal effective dose. Phase IIB studies of combinations aim to measure late phase activity according to a more limited number of dose sizes and different partner drugs in a factorial manner. Both types of Phase II study may or may not also include pharmacokinetic sub-studies, which are generally desirable in order to further evaluate the relevant pharmacokinetic indices, the dose response relationship and the contribution of pharmacokinetic variability to response.

\subsubsection{Phase IIA EBA Studies}

Most published EBA studies have measured the slope of the decline in serial sputum colony counts over the first 2 or 5 days of therapy because the early estimates can best distinguish between the activities of different drugs and different dose sizes of the same drug [74]. Over this early period the bactericidal effect of isoniazid is the greatest encountered with a mean of $0.575 \log _{10} \mathrm{cfu} / \mathrm{ml} \mathrm{sputum}^{-1}$ day $^{-1}(95 \%$ confidence limits: $0.515-0.636)$ [138]. This occurs because the usual dose of isoniazid ( $300 \mathrm{mg}$ daily) is about 20 times larger than the minimum effective dose (MED), when EBA just reaches 0 , whereas most other drugs are given in dose sizes closer to the MED (but this may also be due to it's unique intrinsic potency against the early population). As a result, it has not generally been possible to demonstrate any additive effect of additional agents [74]. Pyrazinamide appears inactive during the first 2 days but is then bactericidal at much the same rate as other drugs [39,74]. These observations suggest that 1) short-term EBA studies can fail to detect sterilizing activity of drugs, and 2) such studies are not likely to be an efficient means of studying combinations. While it is ethically difficult to justify monotherapy with any standard drug for more than 7 days, monotherapy for 14 days with a totally new drug may be acceptable since it will not be used in further treatment, even if drug resistance to it arises. This suggests the possibility of detecting sterilizing activity during monotherapy by extending the duration of the study as indeed has been accomplished in a late analysis of the first 14-day EBA study [74]. On the other hand, the variability of the measurements increases steadily as the counts decline with time, so such a design will not improve prospects for detecting differences between combinations of agents which will generally be much smaller in magnitude than that between a single agent and placebo.

In practice, the risks posed to concurrent placebo controls in a 14-day study (resistance, mortality in $\mathrm{HIV}^{+}$ve patients) are probably too great. Data from historical controls in EBA studies suggest that the mean EBA in these groups was approximately $0[138]$ and to test new agents against this value may the only acceptable solution. Many EBA studies also include isoniazid as a positive control but it is important to understand that this is included simply to demonstrate that the system is working and has results comparable to those obtained in the past. There is no point in demonstrating a significant difference between the EBA of a new drug and that of isoniazid.

In order to establish proof-of-concept, the most reasonable design would be to treat about 15 patients with the new drug at a high dose size for 14 days. This sample size may vary between different centres. A useful rule of thumb is that at a sample size of 15 patients per arm the minimum effect size detectable with $80 \%$ power approximately equals the expected SD of the measurements. Sputum specimens may be collected on alternate days. If the classical 2-day study $\left(\mathrm{EBA}_{0-2}\right)$ differs significantly from 0 , proof-of-concept is established. The rest of the profile of counts can then be examined (Table 7) to confirm that this activity is maintained after 7 days. For isoniazid the profile is markedly curved in shape with activity diminishing after the first two days while for rifampicin it is close to a straight line and for pyrazinamide it is curved but with activity increasing after 2 days. Slopes from days 7-14 may also be tested against 0 or each other. These differences may not achieve significance in these initial studies but may provide some indication of sterilizing activity. If the onset of activity is unusually delayed and EBA completely absent, the duration of the study should be long enough to capture this behaviour which should in any case be predicted from pharmacokinetic considerations or possibly from the mechanism of action.

Table 7. Values of the Early Bactericidal Action (EBA: Mean $\log _{10} \mathrm{cfu} / \mathrm{ml}$ Sputum/Day) of Isoniazid, Ofloxacin, Rifampicin and Pyrazinamide Over 0-2 Days and 25 Days to Show the Shape of the Curve Over the 5Day Period

\begin{tabular}{|c|c|c|c|c|}
\hline Drug & $\begin{array}{c}\text { No. of } \\
\text { Patients }\end{array}$ & $\begin{array}{c}\text { A } \\
\text { EBA } \\
\mathbf{0 - 2} \text { Days }\end{array}$ & $\begin{array}{c}\text { B } \\
\text { EBA } \\
\mathbf{2 - 5} \text { Days }\end{array}$ & $\begin{array}{c}\text { Ratio } \\
\text { A:B }\end{array}$ \\
\hline \hline Isoniazid [77, 140] & 12 & 0.665 & 0.105 & 6.3 \\
\hline Ofloxacin [140] & 11 & 0.142 & 0.112 & 1.26 \\
\hline Rifampicin [48, 141] & 24 & 0.201 & 0.244 & 0.82 \\
\hline Pyrazinamide [77] & 8 & 0.054 & 0.076 & 0.71 \\
\hline
\end{tabular}


Provided that EBA is present, the second stage of phase IIA should be a dose-ranging EBA study in which the dose size is decreased, usually in 2-fold steps from the high level used initially, over the first 2 day (Fig. 5) or for longer periods up to a maximum of 14 days if ethical permission can be obtained. Such a study could estimate the MED, the shape of the dose-response curve and whether the apparently maximum response has been obtained $[49,50]$. If the study were extended to 14 days, it might be possible to determine separate dose-response curves for the early and late phases of bacterial killing, though this has never yet been achieved and would require larger sample sizes. Delayed drug action may complicate these calculations.

Most EBA studies have been carried out on Sub-Saharan African patients [47-50, 74, 77, 138-144], and studies have also been done on patients in the USA [145], Germany [146] and Brazil [147]. Studies have also been done in Hong Kong but with results too variable for useful analysis $[140,148]$.

\subsubsection{Phase IIB 8-Week Studies}

Given the difficulties demonstrating sterilizing activity and the lack of power of comparisons comparing combination therapy in 14-day EBA studies, extending the duration of sputum sampling throughout the intensive phase while sputum cultures still remain positive seems a logical way to maximize the information that can be obtained from such studies. However, if it is expected that these studies will be required to evaluate different dose sizes and also different combinations of companion drugs for a new agent then it is critical that they are designed to be as statistically efficient as possible.
In an 8-week study, possible sputum bacteriological endpoints include the proportion of patients culture negative at 8 weeks, the time to culture conversion or the rate of reduction of colony-forming units (Fig. 5). Of these, the proportion of patients with negative cultures at 8 weeks is the cheapest, simplest and best validated, but is the least powerful. Conceptually, different fixed time points could be used to remedy this but would inevitably be selected arbitrarily and then require re-validation. Speed of sputum conversion, when analysed using survival techniques, requires more frequent sputum cultures (preferably weekly) during the 8 weeks. It seems likely to be more efficient than the proportion negative at 8 weeks but has not been so extensively validated. The most efficient method in theory, but the newest, least developed and most complicated, is the serial sputum colony counting (SSCC) technique in which viable MTB in sputum specimens are counted without decontamination on selective culture medium and the decline of cfu over time estimated by statistical modelling techniques (Fig. 6). This method can in principle distinguish the early and late phases and explicitly account for inter-individual variability in counts, greatly improving the precision of comparisons between treatment groups. To fully realize these gains in power however an optimized sampling scheme of up to ten time points is needed. This is less demanding and more cost-effective than it first appears since the cost of additional samples is usually much less than that of recruiting additional patients. Whether this approach can be as effective using time-to-positivity as a measure of bacterial survival in automated liquid culture systems remains to be explored. If sputum is decontaminated rather than plated on selective medium, it seems likely, though not certain, that the rapidly growing bacteria are se-

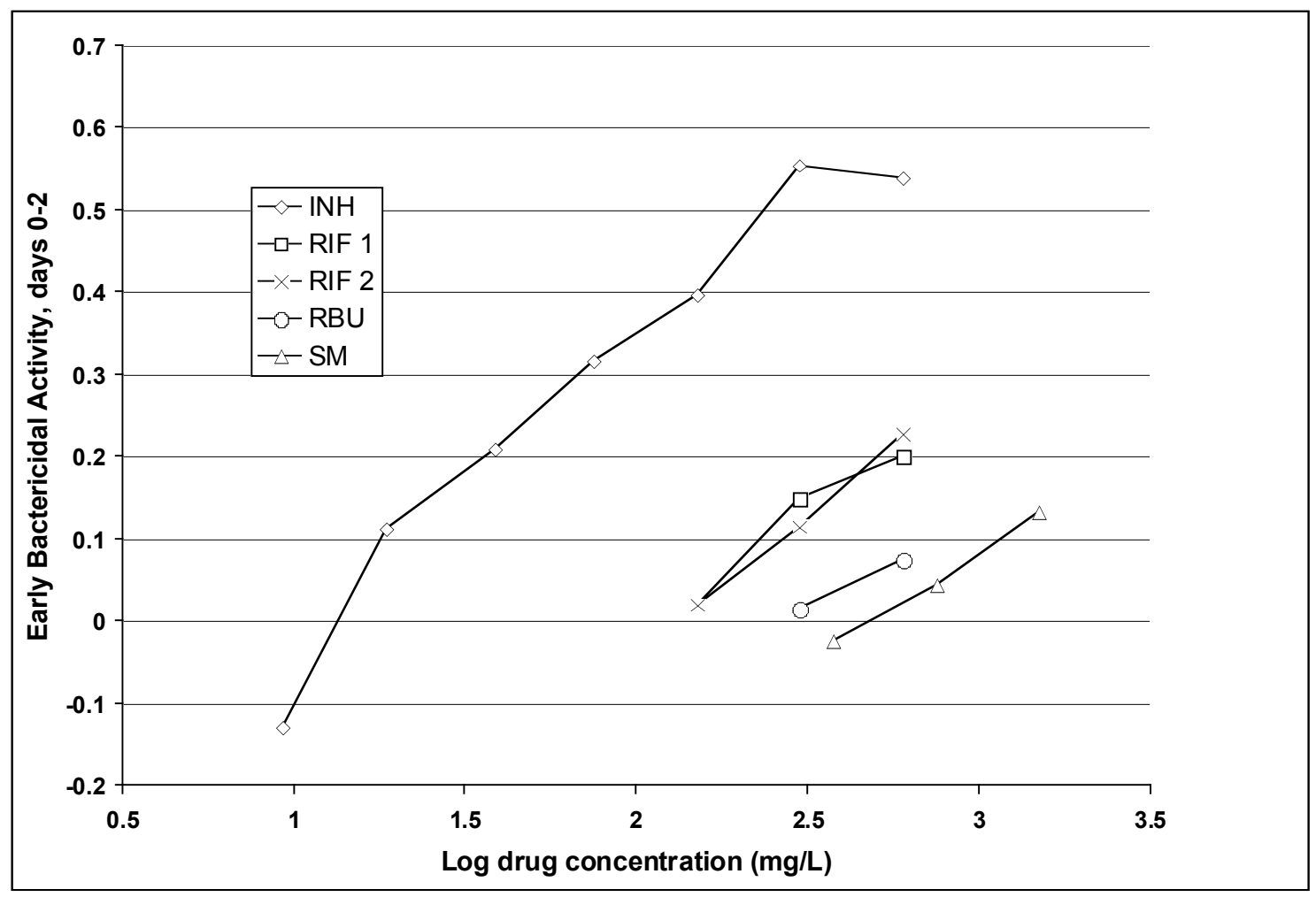

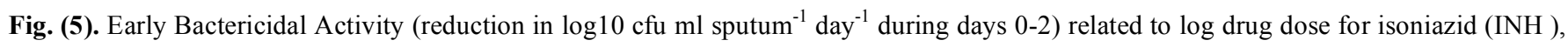
rifampicin on 2 occasions (RIF1 \& RIF2), rifabutin (RBU) and streptomycin (SM). Data from [45-47, 139]. 
lectively killed leaving only the bactericidal activity against persisters (sterilizing activity) measurable [149]. Sample size calculations suggest that the number of patients required per arm to detect realistic differences between regimens with differing sterilizing activity may range from more than 150 for studies based on 2 month culture conversion down to as few as 50 for SSCC [150]. These estimates appear to be borne out by the results of two recent Phase IIB studies in drug-sensitive disease $[109,151]$. However, though it has been suggested that phase IIB trials could be more ethically acceptable in patients with MDR disease, it is likely that the power of such studies would be seriously reduced by the increased variability of response between participants on regimens that include companion drugs of widely variable potency. The smaller number of patients required in SSCC studies could make it feasible to design efficient factorial studies with approximately 25 patients per arm that might, for instance, look at dose size and companion drugs simultaneously in a range of combinations guided by the results of mouse experiments. Such designs could help to accelerate the development process while continuing to gather doseresponse information during the transition from early to late clinical development.

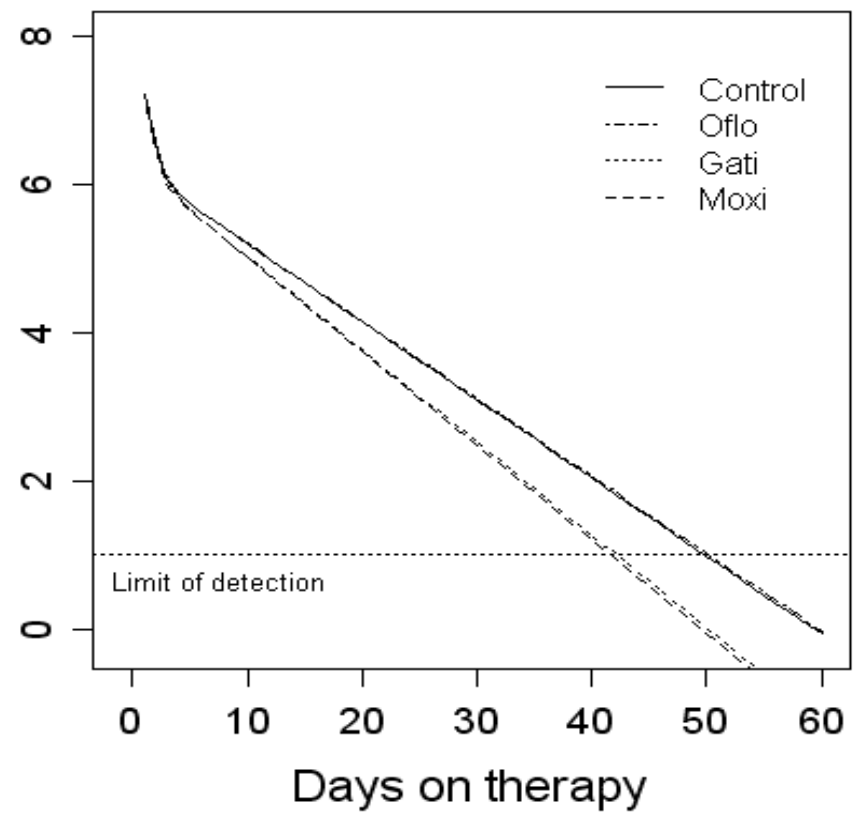

Fig. (6). Bi-exponential fit of cfu counts in a phase IIB study of the fluoroquinolones gatifloxacin, moxifloxacin or ofloxacin substituted for ethambutol. Data from [127].

\subsubsection{Phase III Studies}

Phase III studies will compare a regimen including the new drug either as an addition or substitution in the current standard treatment (2HRZE/4HR), with the dose size and companion drugs optimized on the basis of preclinical data and the results of factorial Phase IIB studies. As noted above, because of the strength of the comparator, demonstrating straightforward superiority of the new regimen given for six months is essentially impossible at practical sample sizes and it has been proposed instead that the aim should be to demonstrate equivalence of a shortened regimen using a combined primary endpoint of failure/relapse. The results of Phase IIB studies will play a crucial role in providing provi- sional support for a shorter duration of the experimental regimen (on the basis that clearance of sputum is faster during the intensive phase) but validation data are lacking to provide accurate forecasting as to the true extent of any reduction in Phase III.

Conceptually then, the goal is to reduce treatment duration to the point where relapse rates are not worse than the comparator. In an equivalence design at a single reduced duration (say 4 months alone) it could be problematic to show that this duration represented the shortest possible regimen using the equivalence limits and it is conceivable that this might result in undertaking a completely new trial at a shorter duration. A more efficient approach might be to use a non-inferiority design with two or more durations (say 3 and 4 months) of the experimental regimen. The outcome of such a trial should be simpler to interpret since the null hypothesis (which is that the new regimen is inferior) could be clearly rejected at one duration but not at another. Such designs despite including more arms would probably be of similar or only modestly increased size compared to two-arm equivalence designs. For purposes other than shortening of treatment, different designs would be appropriate such as equivalence for widely intermittent therapy and perhaps superiority for new forms of delivery such as nano-particles. Similar trial designs for MDR-TB are also possible but complicated due to the complexity of the intervention and ethical issues.

\section{PRIORITIES AND STRATEGIES}

We have implicitly identified a number of linked issues arising during drug development, resolution of which could help to make the process more robust in the future while at the same time identifying important short to medium-term advances in therapy. We can list these as follows:

1. The most important issue is to have a clear model of how chemotherapy for tuberculosis works, and what similarities and differences there are in comparison to non-tuberculous infections. A vital element of the model is the complete suppression of bacterial growth of the bacterial population by modern multi-drug regimens. The process during chemotherapy is just the killing of the initial bacterial population by the drugs. It is this feature together with the longevity of PAE following pulses of most drugs that makes the regimens so robust under a variety of adverse conditions such as minor degrees of poor compliance within a programme of regular drug taking for 6 months. This implies that inhibitors of cell wall synthesis, which include about half of the drugs currently in us, are doomed to be largely ineffective except for the treatment of MDR disease.

2. In vitro assays used in screening and early pre-clinical development should better reflect sterilizing activity. This can only be achieved by further comparative in vitro/in vivo studies of persistence and a better understanding of the mechanisms that induce this response.

3. More detailed subsequent in vitro studies need to incorporate important pharmacodynamic properties such as PAE, a range of relevant environmental conditions such as anaerobiosis and $\mathrm{pH}$ and techniques for evaluating combinations at this stage should be 
explored and improved. Screening and early microbiological tests should be done on cultures resembling those found in sputum and lesions. In particular, they should reflect the switch in gene expression to anaerobic adaptation and to lipids as energy sources. They should also be done at a slightly acid $\mathrm{pH}$ (perhaps of 6.0-6.2) to reflect acid conditions arising in inflammation and in the phagosome [125]. The activity of many drugs (streptomycin, pyrazinamide) is greatly altered by $\mathrm{pH}$. Measurement of PAEs and of plasma binding should be carried out early.

4. Murine models could be further improved by achieving a better understanding of the nature of the relapse process and by the application of techniques for longitudinal data analysis.

5. 14-day phase IIA studies incorporating pharmacokinetics might maximize the quality of dose-response information for drugs which possess EBA and identify potential sterilizing activity in those that do not. This approach has been informative for rifamycins and should also be studied in the fluoroquinolone series.

6. 8-week Phase IIB studies based on survival or modelling techniques may be the only feasible way to quantify sterilizing activity in humans prior to Phase III. Logistical and analytical support for this technique needs to be developed more widely and evaluation against relapse carried out in further studies, for example of higher dosage of rifamycins. This process could be supported by expression profiling studies of sputum bacilli in the early and late phases of therapy and measurements of phenotypic antibiotic tolerance.

7. The merits of equivalence and multiple-duration noninferiority designs for Phase III trials based on relapse need to be explored.

Though resources for tuberculosis research have experienced a resurgence in recent years achieving these goals still represents a challenge. The cost, regulation and complexity of clinical trials have been increasing rapidly while the global tuberculosis situation has shown little improvement and the need for more effective therapy is more urgent than ever. Several conditions will need to be met to make sure that the current pipeline of drugs is translated rapidly into the most effective new combination regimen possible. Firstly, testing of new drugs in combination needs to be promoted preferably prior to and certainly from the onset of Phase IIB but several commercial and regulatory barriers to such an approach need to be overcome and a framework for coordinating such studies adopted by all involved. Second the concept of provisional licensing prior to Phase III should be considered as confidence in Phase IIB data grows, allowing early dissemination of any advance to pilot programs pending definitive evidence of efficacy. Third commercial barriers to rapid uptake of new regimens must be foreseen in advance and mechanisms put in place to ensure that the slow adoption of fully rifampicin-based regimens globally is not repeated. Pharmaceutical, academic, governmental and nongovernmental partners all need to combine their efforts in realising new advances in therapy.
ABBREVIATIONS
$\mathrm{E}=$ Ethambutol (in a regimen)
$\mathrm{EBA}=$ Early Bactericidal Activity
$\mathrm{GKO}=$ Gene knock-out
$\mathrm{H}=$ Isoniazid (in a regimen)
MABA $=$ Microplate Alamar Blue Assay
MDR = Multi-drug resistance
MED $=$ Minimal Effective Dose
MIC = Minimal Inhibitory Concentration
MTB = Mycobacterium tuberculosis
PAE $=$ Post-antibiotic effect
PKPD = Pharmacokinetic-pharmacodynamic
$\mathrm{R}=$ Rifampicin (in a regimen)
SSCC = Serial sputum colony counts
TAACF $=$ Tuberculosis antimicrobial acquisition and co-ordinating facility
$\mathrm{Z} \quad=$ Pyrazinamide (in a regimen)

\section{REFERENCES}

[1] World Health Organization. Stop TB Partnership has provided treatments for 10 million people in 6 years. Weekly Epidemiological Record 2007; 82: 207.

[2] www.tballiance.org

[3] Global Alliance for Tuberculosis Drug Development. Tuberculosis Scientific Blueprint for TB Drug Development. Tuberculosis 2001; 81(Suppl 1): 1-52.

[4] Rich AB. The pathogenesis of tuberculosis $2^{\text {nd }}$ ed. Charles C. Thomas, Springfield 1951.

[5] Grange JM. Pathogenesis of mycobacterial disease in Mycobacteria I Basic Aspects. In: Gangadharam PRJ, Jenkins PA, Eds. Chapman \& Hall, New York 1998.

[6] Balasubramanian V, Wiegeshaus EH, Taylor BT, Smith DW. Pathogenesis of tuberculosis: pathway to apical localization. Tuberc Lung Dis 1994; 75: 168-78.

[7] Ho RS, Fok JS, Harding GE, Smith DW. Host-parasite relationships in experimental airborne tuberculosis. VII. Fate of Mycobacterium tuberculosis in primary lung lesions and in primary lesionfree lung tissue infected as a result of bacillemia. J Infect Dis 1978; 138: 237-41.

[8] Canetti G. The tubercle bacillus in the pulmonary lesion of man. Springer, New York, Chapters 1 \& 2, 1955.

[9] Converse PJ, Dannenberg AM Jr, Estep JE, et al. Cavitary tuberculosis produced in rabbits by aerosolized virulent tubercle bacilli. Infect Immun 1996; 64: 4776-87.

[10] Hart PD, Young MR, Gordon AH, Sullivan KH. Inhibition of phagosome-lysosome fusion in macrophages by certain mycobacteria can be explained by inhibition of lysosomal movements observed after phagocytosis. J Exp Med 1987; 166: 933-46.

[11] Shamputa IC, Jugheli L, Sadradze N, et al. Mixed infection and clonal representativeness of a single sputum sample in tuberculosis patients from a penitentiary hospital in Georgia. Respir Res 2006; 7: 99.

[12] Garton NJ, Waddell SJ, Sherratt AL, et al. Cytological and transcript analyses reveal fat and lazy persister-like bacilli in tuberculous sputum. PLoS Med 2008; 5: e75.

[13] Medical Research Council. Streptomycin treatment of pulmonary tuberculosis. Br Med J 1948; 2: 769-82.

[14] Fox W, Sutherland I, Daniels M. A five-year assessment of patients in a controlled trial of streptomycin in pulmonary tuberculosis. Q J Med 1954; 23: 347-66.

[15] Mitchison DA. Treatment of tuberculosis. The Mitchell Lecture 1979. J Roy Coll Phys 1980; 14: 91-9. 
[16] Crofton J. Tuberculosis undefeated. Br Med J 1960; 2: 679-87.

[17] International Union again Tuberculosis. An international investigation of the efficacy of chemotherapy in previously untreated patients with pulmonary tuberculosis. Bull Int Union Tuberc 1964; 34: 1-191.

[18] East African/British Medical Research Council. Isoniazid with thiacetazone (thioacetazone) in the treatment of pulmonary tuberculosis in East Africa - fifth investigation. Tuberculosis 1970; 51: 123-51.

[19] East African/British Medical Research Council. Controlled clinical trial of short-course (6-month) regimens of chemotherapy for treatment of pulmonary tuberculosis. Lancet 1972; 20:1079-85.

[20] Fox W, Ellard GA, Mitchison DA. Studies on the treatment of tuberculosis undertaken by the British Medical Research Council Tuberculosis Units, 1946-1986, with relevant subsequent publications. Int J Tuberc Lung Dis 1999; 3(Suppl): S231-S276.

[21] Mitchison DA. Assessment of new sterilizing drugs for treating pulmonary tuberculosis by culture at 2 months. Am Rev Respir Dis 1993; 147: 1062-63.

[22] Mitchison DA. Modern methods for assessing the drugs used in the chemotherapy of mycobacterial disease. J Appl Bacteriol 1996; 81: 72-80S.

[23] Phillips P, Fielding K. The evaluation of culture conversion during treatment for tuberculosis as a surrogate for treatment failure Int $\mathrm{J}$ Tuberc Lung Dis 2007; 11: S161-S162.

[24] East African/British Medical Research Council. Controlled clinical trial of four short-course regimens of chemotherapy for two durations in the treatment of pulmonary tuberculosis. Third Study. Second Report. Tuberculosis 1980; 61: 59-69.

[25] East African/British Medical Research Councils. Controlled clinical trial of five short-course (4-month) chemotherapy regimens in pulmonary tuberculosis: Second report of the 4th study. Am Rev Respir Dis 1981; 123: 165-70.

[26] Singapore Tuberculosis Service/British Medical Research Council. Long-term follow-up of a clinical trial of six-month and fourmonth regimens of chemotherapy in the treatment of pulmonary tuberculosis. Am Rev Respir Dis 1986; 133: 779-83.

[27] Hong Kong Chest Service/British Medical Research Council. Controlled trial of 2, 4 \& 6 months of pyrazinamide in 6-month, $3 \mathrm{x}$ weekly regimens for smear-positive pulmonary tuberculosis, including an assessment of a combined preparation of isoniazid, rifampicin \& pyrazinamide. Am Rev Respir Dis 1991; 143: 700-6.

[28] Jindani A, Nunn AJ, Enarson DA. Two 8-month regimens of chemotherapy for the treatment of newly diagnosed pulmonary tuberculosis: international multicentre randomised trial. Lancet 2004; 364:1244-51.

[29] Fox W. Whither short-course chemotherapy? Br J Dis Chest 1981; 75: 331-57.

[30] Gelband H. Regimens of less than six months for treating tuberculosis. Cochrane Database Syst Rev 1999; Issue 4.

[31] Telenti A. Genetics of drug resistant tuberculosis. Thorax 1998; 53: 793-7.

[32] Vilchèze $\mathrm{C}$, Wang $\mathrm{F}$, Arai $\mathrm{M}$, et al. Transfer of a point mutation in Mycobacterium tuberculosis inhA resolves the target of isoniazid. Nat Med 2006; 12: 1027-31.

[33] Artsimovitch I, Vassylyeva MN, Svetlov D, et al. Allosteric modulation of the RNA polymerase catalytic reaction is an essential component of transcription control by rifamycins. Cell 2005; 122: $351-63$.

[34] Barry CE, Boshoff HIM, Dowd CS. Prospects for clinical introduction of nitroimadazole antibiotics for the treatment of tuberculosis. Curr Pharm Des 2004; 10: 3239-62.

[35] Andries K, Verhasselt P, Guillemont J, et al. A diarylquinoline drug active on the ATP synthase of Mycobacterium tuberculosis. Science 2005; 307: 223-7.

[36] Zhang Y, Mitchison D. The curious characteristics of pyrazinamide: a review. Int J Tuberc Lung Dis 2003; 7: 6-21.

[37] Zhang Y, Wade MM, Scorpio A, Zhang H, Sun Z. Mode of action of pyrazinamide: disruption of Mycobacterium tuberculosis membrane transport and energetics by pyrazinoic acid. J Antimicrob Chemother 2003; 52: 790-5.

[38] Hu Y, Coates AR, Mitchison DA. Sterilising action of pyrazinamide in models of dormant and rifampicin-tolerant Mycobacterium tuberculosis. Int J Tuberc Lung Dis 2006; 10: 317-22.

[39] Mitchison DA. The action of antituberculosis drugs in short-course chemotherapy. Tuberculosis $1985 ; 66: 219-25$.
[40] Kubendiran G, Paramasivan CN, Sulochana S, Mitchison DA. Moxifloxacin and gatifloxacin in an acid model of persistent $M y$ cobacterium tuberculosis. J Chemother 2006; 18: 617-23.

[41] Mitchison DA, Ellard GA. Antituberculous drugs. In: Reeves DA, Phillips I, Williams JD, Wise R, Eds. Laboratory Methods in Antimicrobial Chemotherapy: Churchill Livingstone, Edinburgh 1978; pp. 244-8.

[42] Kim M-K, Nightingale $\mathrm{CH}$. Pharmacokinetics and pharmacodynamics of the fluoroquinolones. In The Quinolones, $3^{\text {rd }}$ ed. Academic Press 2000; pp. 169-202.

[43] Mitchison DA. Development of rifapentine: the way ahead. Int J Tuberc Lung Dis 1998; 2: 612-25.

[44] Pyle MM, Pfuetze KH, Pearlman MD, Huerga J de la, Hubble RH. A four-year clinical investigation of ethambutol in initial and retreatment cases of tuberculosis: efficacy, toxicity, and bacterial resistance. Am Rev Respir Dis 1966; 93: 428-41.

[45] Leibold JE. The ocular toxicity of ethambutol and its relation to dose. Ann NY Acad Sci 1966; 135: 904-9.

[46] Bobrowitz ID, Gokulanathan KS. Ethambutol in the retreatment of pulmonary tuberculosis. Dis Chest $1965 ; 48: 239-50$.

[47] Donald PR, Sirgel FA, Venter A, et al. The early bactericidal activity of streptomycin. Int J Tuberc Lung Dis 2002; 6: 693-8.

[48] Sirgel FA, Fourie PB, Donald PR, et al. the Rifapentine EBA Collaborative Study Group. The early bactericidal activities of rifampicin and rifapentine in pulmonary tuberculosis. Am J Respir Crit Care Med 2005; 172: 128-35.

[49] Donald PR, Sirgel FA, Botha FJ, et al. The early bactericidal activity of isoniazid related to its dose size in pulmonary tuberculosis. Am J Respir Crit Care Med 1997; 156: 895-900.

[50] Donald PR, Sirgel FA, Venter A, et al. The influence of human Nacetyltransferase genotype on the early bactericidal activity of isoniazid. Clin Infect Dis 2004; 15: 1425-30.

[51] Kimerling ME, Phillips P, Patterson P, Hall M, Robinson CA, Dunlap NE. Low serum antimycobacterial drug levels in non-HIVinfected tuberculosis patients. Chest 1998; 113: 1178-83.

[52] Mehta JB, Shantaveerapa H, Byrd RP Jr, Morton SF, Fountain F, Roy TM. Utility of rifampicin serum concentrations in the treatment and follow-up of active pulmonary tuberculosis in patients who were slow to respond to routine directly observed therapy. Chest 2001; 120: 1520-4.

[53] Peloquin C. What is the 'right' dose of rifampicin. Int J Tuberc Lung Dis 2004; 7: 3-5.

[54] Verbist L. Pharmacological study of rifampicin after repeated high dosage during intermittent combined therapy. I. Variation of the rifampicin serum levels (947 determinations). Respiration 1971; 28: S7-17.

[55] Kreis B, Pretet S, Birenbaum J, et al. Two three-month treatment regimens for pulmonary tuberculosis. Bull Int Union Tuberc 1976; 51: 71-5.

[56] Feldman WH, Hinshaw HC, Karlson AG. Frequency of administration of streptomycin. Am Rev Tuberc 1947; 55: 435-43.

[57] Tuberculosis Chemotherapy Centre, Madras. A concurrent comparison of isoniazid plus PAS with three regimens of isoniazid alone in the domiciliary treatment of pulmonary tuberculosis in South India. Bull World Health Organization 1960; 23: 535-85.

[58] Indian Council of Medical Research/British Medical Research Council South India. A controlled trial of short-course regimens of chemotherapy in patients receiving ambulatory treatment or undergoing radical surgery for tuberculosis of the spine. Ind J Tuberc 1989; 36: 1-21.

[59] Medical Research Council Working Party on Tuberculosis of the Spine. $12^{\text {th }}$ Report. Controlled trial of short-course regimens of chemotherapy in the ambulatory treatment of spinal tuberculosis. J Bone Joint Surg [Br] 1993; 75: 240-8.

[60] Medical Research Council Working Party on Tuberculosis of the Spine. $14^{\text {th }}$ report. Five year assessment of controlled trials of shortcourse chemotherapy regimens of 6,9 or 18 months duration for spinal tuberculosis in patients ambulatory from the start of undergoing radical surgery. Int Orthop 1999; 23: 73-81.

[61] Medical Research Council. Streptomycin treatment of tuberculous meningitis. Lancet 1948; 1: 582-96.

[62] Tanzania/British Medical Research Council. A controlled trial of a 4-weekly supplement of rifampicin, pyrazinamide and streptomycin in the continuation phase of a 7-month daily chemotherapy regimen for pulmonary tuberculosis. S Afr Med J 1996; 86: 960-5. 
[63] Acocella G, Conti R, Luisetti M, Pozzi E, Grassi C. Pharmacokinetic studies on antituberculosis regimens in humans. I. Absorption and metabolism of the compounds used in the initial intensive phase of the short-course regimens: single administration study. Am Rev Respir Dis 1985; 132: 510-15.

[64] Nuermberger EL, Yoshimatsu T, Tyagi S, et al. Moxifloxacincontaining regimen greatly reduces time to culture conversion in murine tuberculosis. Am J Respir Crit Care Med 2004; 169: 42146.

[65] Tam CM, Chan SL, Kam KM, Goodall RL, Mitchison DA. Rifapentine and isoniazid in the continuation phase of a 6-month regimen. Final report at 5 years: prognostic value of various measures. Int J Tuberc Lung Dis 2002; 6: 3-10.

[66] The Tuberculosis Trials Consortium. Rifapentine and isoniazid once a week $v s$ rifampicin and isoniazid twice a week for treatment of drug-susceptible pulmonary tuberculosis in HIV-negative patients: a randomised clinical trial. Lancet 2002; 360: 528-34.

[67] Mitchison DA, Dickinson JM. Laboratory aspects of intermittent drug therapy. Postgrad Med J 1971; 47: 737-41.

[68] Ginsburg AS, Lee J, Woolwine SC, Grosset JH, Hamzeh FM, Bishai WR. Modeling in vivo pharmacokinetics and pharmacodynamics of moxifloxacin therapy for Mycobacterium tuberculosis infection by using a novel cartridge system. Antimicrob Agents Chemother 2005; 49: 853-56.

[69] Awaness AM, Mitchison DA. Cumulative effects of pulsed exposures of Mycobacterium tuberculosis to isoniazid. Tuberculosis 1973; 54: 153-58.

[70] Tuberculosis Chemotherapy Centre, Madras. A controlled comparison of a twice-weekly and three once-weekly regimens in the initial treatment of pulmonary tuberculosis. Bull World Health Organ 1970; 43: 143-206.

[71] Tuberculosis Chemotherapy Centre, Madras. A controlled comparison of two fuly supervised once-weekly regimens in the treatment of newly diagnosed pulmonary tuberculosis. Tuberculosis 1973; 54: $23-45$.

[72] Vernon A, Burman W, Benator D, Khan A, Bozeman L. Acquired rifampicin monoresistance in patients with HIV-related tuberculosis treated with once-weekly rifapentine and isoniazid. Tuberculosis trials consortium. Lancet 1999; 353: 1843-7.

[73] Mitchison DA. How drug resistance emerges as a result of poor compliance during short course chemotherapy for tuberculosis. Int J Tuberc Lung Dis 1998; 2: 10-5.

[74] Jindani A, Doré CJ, Mitchison DA. The bactericidal and sterilising activities of antituberculosis drugs during the first 14 days. Am J Respir Crit Care Med 2003; 167: 1348-54.

[75] Davies GR, Brindle R, Khoo SH, Aaron LJ. Improved precision of early pharmacodynamic measures in tuberculosis using non-linear mixed effects analysis. Antimicrob Agents Chemother 2006; 50: 3154-6.

[76] Brindle R, Odhiambo J, Mitchison D. Serial counts of Mycobacterium tuberculosis in sputum as surrogate markers of the sterilising activity of rifampicin and pyrazinamide in treating pulmonary tuberculosis. BMC Pulm Med 2001; 1, 2. (www.biomedcentral.com/ $1471-2466 / 1 / 2$ ).

[77] Jindani A, Aber VR, Edwards EA, Mitchison DA. The early bactericidal activity of drugs in patients with pulmonary tuberculosis. Am Rev Respir Dis 1980; 121: 939-49.

[78] Ferebee SH. Controlled chemoprophylaxis trials in tuberculosis: a general review. Adv Tuberc Res 1970; 17: 28-106.

[79] Mitchison DA. Role of individual drugs in the chemotherapy of tuberculosis. Int J Tuberc Lung Dis 2000; 4: 796-806.

[80] Dickinson JM, Mitchison DA. Experimental models to explain the high sterilizing activity of rifampicin in the chemotherapy of tuberculosis. Am Rev Respir Dis 1981; 123: 367-71.

[81] Jayaram R, Gaonkar S, Kaur P, et al. Pharmacokineticspharmacodynamics of rifampicin in an aerosol infection model of tuberculosis. Antimicrob Agents Chemother 2003; 47: 2118-24.

[82] Jayaram R, Shandil RK, Gaonkar S, et al. Isoniazid pharmacokinetics-pharmacodynamics in an aerosol infection model of tuberculosis. Antimicrob Agents Chemother 2005; 48: 2951-7.

[83] Shandil RK, Jayaram R, Kaur P, et al. Moxifloxacin, ofloxacin, sparfloxacin, and ciprofloxacin against Mycobacterium tuberculosis: evaluation of in vitro and pharmacodynamic indices that best predict in vivo efficacy. Antimicrob Agents Chemother 2007; 51: 576-82.
[84] Mitchison DA. Plasma concentrations of isoniazid in the treatment of tuberculosis. In: Davies DS, Prichard BNC, Eds. Biological effects of drugs in relation to their plasma concentrations. British Pharmacological Society: Macmillan, London 1973; pp. 171-82.

[85] Mitchison DA. Antimicrobial therapy of tuberculosis: justification for currently recommended treatment regimens. Seminars Respir Crit Care Med 2004; 25: 307-15.

[86] Chang KC, Leung CC, Yew WW, Ho SC, Tam CM. A nested casecontrol study on treatment-related risk factors for early relapse of tuberculosis. Am J Respir Crit Care Med 2004; 170: 1124-30.

[87] Butcher PD. Microarrays for Mycobacterium tuberculosis. Tuberculosis (Edinb) 2004; 84: 131-7.

[88] Sherman DR, Voskuil M, Schnappinger D, Liao R, Harrell MI, Schoolnik GK. Regulation of the Mycobacterium tuberculosis hypoxic response gene encoding $\alpha$-crystallin. Proc Natl Acad Sci USA 2001; 98: 7534-9.

[89] Crowle AJ, Sbarbaro JA, May MH. Effects of isoniazid and of ceforanide against virulent tubercle bacilli in cultured human macrophages. Tuberculosis 1988; 69: 15-25.

[90] Sbarbaro JA, Iseman MD, Crowle AJ. The combined effect of rifampicin and pyrazinamide within the human macrophage. Am Rev Respir Dis 1992; 146: 1448-51.

[91] Sbarbaro JA, Iseman MD, Crowle AJ. Combined effect of pyrazinamide and ofloxacin within the human macrophage. Tuberc Lung Dis 1996; 77: 491-5.

[92] Herbert D, Paramasivan CN, Venkatesan P, Kubendiran G, Prabhakar R, Mitchison DA. Bactericidal action of ofloxacin, sulbactam-ampicillin, rifampicin, and isoniazid on logarithmic- and stationary-phase cultures of Mycobacterium tuberculosis. Antimicrob Agents Chemother 1996; 40: 2296-9.

[93] Paramasivan CN, Sulochana S, Kubendiran G, Venkatesan P, Mitchison DA. Bactericidal action of gatifloxacin, rifampicin, and isoniazid on logarithmic-and stationary-phase cultures of Mycobacterium tuberculosis. Antimicrob Agents Chemother 2005; 49: 62731.

[94] Kubendiran G, Paramasivan CN, Sulochana S, Mitchison DA. Moxifloxacin and gatifloxacin in an acid model of persistent $\mathrm{My}$ cobacterium tuberculosis. J Chemother 2006; 18: 617-23.

[95] Nuermberger E, Rosenthal I, Tyagi S, et al. Combination chemotherapy with the nitroimidazopyran PA-824 and first-line drugs in a murine model of tuberculosis. Antimicrob Agents Chemother 2006; 50: 2621-5.

[96] Bhusan Y, Shiohira CM, Yamane N. Determination of in vitro synergy when three antimicrobial agents are combined against $M y$ cobacterium tuberculosis. Int J Antimicrob Agents 2005; 26: 29227.

[97] Guy A, Dickinson JM, Mitchison DA. Turning intermittent regimens into daily regimens using blister-packs. An exploration in murine tuberculosis. Tuberc Lung Dis 1993; 74: 310-6.

[98] Santha T, Rehman F, Mitchison DA, Sarma GR, Reetha AM, Prabhaker R. Tuberculosis Research Centre, Indian Council of Medical Research. Split-drug regimens for the treatment of patients with sputum smear-positive pulmonary tuberculosis--a unique approach. Trop Med Int Health 2004; 9: 551-8.

[99] Biomarkers Definitions Working Group. Biomarkers and surrogate endpoints:preferred definitions and conceptual framework. Clin Pharm Ther 2001; 69: 89-95.

[100] Grosset J. The sterilizing activity of rifampicin and pyrazinamide in experimental short-course chemotherapy. Bull Int Union Tuberc 1978; 53: 5-12.

[101] Molenberghs G, Burzykowski T, Alonso A, Buyse M. A perspective on surrogate endpoints in controlled clinical trials. Stat Methods Med Res 2004; 13: 177-206.

[102] Sheiner LB. Learning vs confirming in clinical drug development. Clin Pharm Ther 1997; 61: 275-91.

[103] Zhang L, Sinha V, Forgue ST, et al. Model-based drug development: the road to quantitative pharmacology. J Pharmacokinet Pharmacodyn 2006; 33: 369-93.

[104] Royston P, Altman DG, Sauerbrei W. Dichotomizing continuous predictors in multiple regression: a bad idea. Stat Med 2006; 25 : 127-41.

[105] Ragland DR. Dichotomizing continuous outcome variables: dependence of the magnitude of association and statistical power on the cutpoint. Epidemiology 1992; 3: 434-40. 
[106] Durban Immunotherapy Trial Group. Immunotherapy with Mycobacterium vaccae in patients with newly diagnosed pulmonary tuberculosis: a randomised controlled trial. Lancet 1999; 354: 116-9.

[107] Holtz TH, Sternberg M, Kammerer S, et al. Time to sputum culture conversion in multidrug-resistant tuberculosis: predictors and relationship to outcome. Ann Int Med 2006; 14: 650-9.

[108] Wallis RS, Kyambadde P, Johnson JL, et al., A study of the safety, immunology, virology and microbiology of adjunctive etanercept in HIV-1-associated tuberculosis. AIDS 2004; 18: 257-64.

[109] Rustomjee R, Lienhardt C, Kanyok T, et al.; the Gatifloxacin for TB (OFLOTUB) study team. A phase II study of the sterilising activities of ofloxacin, gatifloxacin and moxifloxacin in pulmonary tuberculosis. Int J Tuberc Lung Dis 2008; 12: 128-36.

[110] Gelband H. Regimens of less than six months for treating tuberculosis. Cochrane Database Syst Rev 1999; 4

[111] Reddy VM, Nadadhur G, Daneluzzi D, Dimova V, Gangadharam PR. Antimycobacterial activity of a new rifamycin derivative, 3-(4cinnamylpiperazinyl iminomethyl) rifamycin SV (T9). Antimicrob Agents Chemother 1995; 39: 2320-4.

[112] Dimova V, Dobrev P, Kalfin E, Vlasov V. Therapeutic effect of 3/4-cinnamyl-1-piperazinyl iminomethyl) rifamycin SV on generalized tuberculosis in guinea pigs. Recent Advances in Chemotherapy, Proceedings of the $18^{\text {th }}$ International Congress of Chemotherapy, Washington, D.C.: American Society for Microbiology 1994.

[113] Dimova V, Stefanova P, Valova N. Pharmacokinetic studies in experimental animals on cinnamyl rifampicinamycin derivative (T9). Recent Advances in Chemotherapy. Proceedings of the $18^{\text {th }}$ International Congress of Chemotherapy Washington DC: American Society for Microbiology 1994.

[114] Gangadharam PRJ. New Drugs and Strategies for Chemotherapy of Tuberculosis. In: Gangadharam PRJ, Jenkins PA, Eds. Mycobacteria II Chemotherapy: Chapman \& Hall, New York 1998.

[115] Machowski EE, Dawes S, Mizrahi V. TB tools to tell the talemolecular genetic methods for mycobacterial research. Int J Biochem Cell Biol 2005; 37: 54-68.

[116] Murry JP, Rubin EJ. New genetic approaches shed light on TB virulence. Trends Microbiol 2005; 13: 366-72.

[117] Williams KJ, Duncan K. Current strategies for identifying and validating targets for new treatment-shortening drugs for TB. Curr Mol Med 2007; 7: 297-307.

[118] Goldman RC, Laughon BE, Reynolds R, et al. Programs to facilitate tuberculosis drug discovery: The tuberculosis antimicrobial acquisition and coordinating facility. Infect Dis Drug Targets 2007. Also Tuberculosis Antimicrobial Acquisition and Co-ordinating Facility (http :// www.taacf.org).

[119] Schaefer WB. The effect of isoniazid on growing and resting tubercle bacilli. Am Rev Tuberc 1954; 69: 125-7.

[120] Hobby GL, Lenert TF. The in vitro action of antituberculous agents against multiplying and non-multiplying microbial cells. Am Rev Tuberc 195776 1031-48.

[121] Mitchison DA. Titration of strains of tubercle bacilli against isoniazid. Lancet 1952; 858-60.

[122] McDermott, Tompsett R. Activiation of pyrazinamide and nicotinamide in acidic environments in vitro. Am Rev Tuberc 1954; 70: 748-54.

[123] Mwandumba HC, Russell DG, Nyirenda MH, et al. Mycobacterium tuberculosis resides in nonacidified vacuoles in endocytically competent alveolar macrophages from patients with tuberculosis and HIV infection. J Immunol 2004; 172: 4592-8.

[124] Wayne LG. Dormancy of Mycobacterium tuberculosis and latency of disease. Eur J Clin Microbiol Infect Dis 1994; 13: 908-14.

[125] Wayne GL, Hayes LG. An in vitro model for sequential study of shiftdown of Mycobacterium tuberculosis through two stages of nonreplicating persistence. Infect Immun 1996; 64: 2062-9.

[126] Dhillon J, Allen BW, Hu YM, Coates ARM, Mitchison DA. Metronidazole has no antibacterial effect in Cornell model murine tuberculosis. Int J Tuberc Lung Dis 1998; 2: 736-42.

[127] Tsai MC, Chakravarty S, Zhu G, et al. Characterization of the tuberculous granuloma in murine and human lungs: cellular composition and relative tissue oxygen tension. Cell Microbiol 2006; 8: 218-32.

[128] Hu Y, Mangan JA, Dhillon J, et al. Detection of mRNA transcripts and active transcription in persistent Mycobacterium tuberculosis induced by exposure to rifampin or pyrazinamide. J Bacteriol 2000; 182: 6358-65.
[129] $\mathrm{Hu}$ Y, Coates ARM, Mitchison DA. Sterilizing activities of fluoroquinolones against rifampicin-tolerant populations of Mycobacterium tuberculosis. Antimicrob Agents Chemother 2003; 47: 653-7.

[130] Baohong JI, Truffot-Pernot C, Lacroix C, et al. Effectiveness of rifampicin, rifabutin, and rifapentine for preventive therapy of tuberculosis in mice. Am Rev Respir Dis 1993; 148: 1541-6.

[131] Lenaerts AJM, Gruppo V, Brooks JV, Orme IM. Rapid in vivo screening of experimental drugs for tuberculosis using gama interferon gene-disrupted mice. Antimicrob Agents Chemother 2003; 47: 783-5.

[132] Nuermberger E, Grosset J. Pharmacokinetic and pharmacodynamic issues in the treatment of mycobacterial infections. Eur J Clin Microbiol Infect Dis 2004; 23: 243-55.

[133] Dhillon J, Dickinson JM, Sole K, Mitchison DA. Preventive chemotherapy of tuberculosis in Cornell model mice with combinations of rifampicinampin, isoniazid, and pyrazinamide. Antimicrob Agents Chemother 1996; 40: 552-5

[134] Scanga CA, Mohan VP, Joseph H, Yu K, Chan J, Flynn JL. Reactivation of latent tuberculosis: variations on the Cornell murine model. Infect Immun 1999; 67: 4531-8.

[135] Nuermberger EL, Yoshimatsu T, Tyagi S, et al. Moxifloxacincontaining regimens of reduced duration produce a stable cure in murine tuberculosis. Am J Respir Crit Care Med 2004; 170: 11314.

[136] Davies GR, Pym AS, Mitchison DA, Nuermberger EL, Grosset JH. Evaluation of new antituberculosis drugs in mouse models. Antimicrob Agents Chemother 2007; 51: 403-4.

[137] Wallis RS, Visoniazidas SA, Johnson JL, et al. Whole blood bactericidal activity during treatment of pulmonary tuberculosis. J Infect Dis 2003; 187: 270-8.

[138] Sirgel F, Venter A, Mitchison D. Sources of variation in studies of the early bactericidal activity of antituberculosis drugs. J Antimicrob Chemother 2001; 47: 177-82.

[139] Botha FJH, Sirgel FA, Parkin DP, Van de Wal BW, Donald PR, Mitchison DA. Early bactericidal activity of ethambutol, pyrazinamide and the fixed combination of isoniazid, rifampicin and pyrazinamide (rifater) in patients with pulmonary tuberculosis. S Afr Med J 1996; 86: 155-8.

[140] Sirgel FA, Donald PR, Odhiambo J, et al., and the EBA Collaborative Study Group. A multicentre study of the early bactericidal activity of anti-tuberculosis drugs. J Antimicrob Chemother 2000; 45: 859-70

[141] Sirgel FA, Botha FJH, Parkin DP, et al. The early bactericidal activity of rifabutin in patients with pulmonary tuberculosis measured by sputum viable counts. A new method of drug assessment. J Antimicrob Chemother 1993; 32: 867-75.

[142] Donald P, Sirgel FA, Venter A, et al. Early bactericidal activity of amoxicillin in combination with clavulanic acid in patients with sputum smear-positive pulmonary tuberculosis. Scand J Infect Dis 2001; 33: 466-9.

[143] Donald PR, Sirgel FA, Kanyok TP, et al. The early bactericidal activity of paromomycin (aminosidine) in patients with smearpositive pulmonary tuberculosis. Antimicrob Agents Chemother 2000; 44: 3285-7.

[144] Gosling RD, Ulso LO, Sam NE, et al. The bactericidal activity of moxifloxacin in patients with pulmonary tuberculosis. Am J Respir Crit Care Med 2003; 168: 1342-5.

[145] Chambers HF, Kocagöz T, Sipit T, Turner J, Hopewell PC. Activity of amoxicillin/clavulanate in patients with tuberculosis. Clin Inf Dis 1998; 26: 874-7.

[146] Pletz MWR, Roux AD, Roth A, Neumann K-H, Mauch H, Lode H. Early bactericidal activity of moxifloxacin in treatment of pulmonary tuberculosis: a prospective, randomized study. Antimicrob Agents Chemother 2004; 48: 780-2.

[147] Dietze R, Teixeira L, Rocha LMC, et al. Safety and bactericidal activity of rifalazil in patients with pulmonary tuberculosis. Antimicrob Agents Chemother 2001; 45: 1972-6.

[148] Chan SL, Yew WW, Ma WK, et al. The early bactericidal activity of rifabutin measured by sputum viable counts in Hong Kong patients with pulmonary tuberculosis. Tubercle Lung Dis 1992; 73: 33-8.

[149] Mitchison DA. Early bactericidal activity and sterilizing activity of ciprofloxacin in pulmonary tuberculosis. Am J Respir Crit Care Med 1995; 151: 921 . 
[150] Davies GR, Khoo SH, Aarons LJ. Optimal sampling strategies for early pharmacodynamic measures in tuberculosis. J Antimicrob Chemother 2006; 58: 594-600.
[151] Burman WJ, Goldberg S, Johnson JL, et al., and the Tuberculosis Trials Consortiumet. Moxifloxacin vs ethambutol in the first two months of treatment for pulmonary tuberculosis. Am J Respir Crit Care Med 2006; 174: 331-8.

(C) Mitchison and Davies; Licensee Bentham Open.

This is an open access article licensed under the terms of the Creative Commons Attribution Non-Commercial License (http://creativecommons.org/licenses/by$\mathrm{nc} / 3.0 /$ ) which permits unrestricted, non-commercial use, distribution and reproduction in any medium, provided the work is properly cited. 